\title{
Padrões isotópicos Sm-Nd no limite entre os terrenos Alto Pajeú e Alto Moxotó (PB)
}

\author{
Sérgio Wilians de Oliveira Rodrigues ${ }^{1}$ \& Benjamim Bley de Brito Neves ${ }^{2}$
}

\begin{abstract}
Resumo A utilização de padrões isotópicos de Sm-Nd na porção leste da Zona Transversal da Província Borborema (porção nordeste da Plataforma Sul Americana) auxilia na definição das unidades geotectônicas/ geológicas devido aos padrões isótopicos distintos existentes nas mesmas. O primeiro padrão isotópico (Grupo I ) é observado em ortognaisses graniticos e rochas supracrustais do Terreno Alto Pajeú (TAP) caracteriza-se por idades $\mathrm{T}_{\mathrm{DM}}$ entre 1,0 a $2,0 \mathrm{Ga}, \mathrm{CNd}_{(0)}$ fortemente negativos $(-20)$ e razões ${ }^{147} \mathrm{Sm} /{ }^{144} \mathrm{Nd}$ maiores que 0,12 indicativas de póssivel fracionamento isotópico. O outro padrão isotópico (Grupo II) é observado em ortognaisse variados (em rochas supracrustais do Complexo Sertânia) do Terreno Alto Moxotó (TAM) exibe assinaturas com idades $T_{\mathrm{DM}}$ mais antigas com valores entre 3,0 a 2,0 Ga, valores fortementes negativos de $\epsilon_{\mathrm{Nd}}(0)$ com valores entre $-20,0$ e $-35,0$, e valores de ${ }^{147} \mathrm{Sm} /{ }^{144} \mathrm{Nd}$ menores do que a do grupo I, concentrados no intervalo de 0,12 e 0,08 . Os valores de $\mathrm{CNd}_{(\mathrm{t})}$ calculados para o Grupo I ( $\mathrm{t}=950 \mathrm{Ma}$ ) varia de $-14,0$ a 1,28 e para o Grupo II ( $\mathrm{t}=2000 \mathrm{Ma})$ varia de $-11,28 \mathrm{a}+1,73$. As assinaturas isótopicas descritas também são observadas nos corpos graníticos brasilianos (de idade Ediacariana) da região indicando a participação do Terreno Alto Pajeú e Terreno Alto Moxotó como fonte crustais para os eventos magmáticos da Zona Transversal. Os padrões isótopicos de $\mathrm{Nd}$ encontram respaldo em outros métodos geocronológicos, tais como $\mathrm{Rb}-\mathrm{Sr}$ e U-Pb.
\end{abstract}

Palavras-chave: Padrões isotópicos de Sm-Nd, Província Borborema, Zona Transversal, Terreno Alto Pajeú e Terreno Alto Moxotó.

\begin{abstract}
Sm-Nd isotopic patterns in the limit between the Alto Pajeú terrane and Alto Moxotó terrane. Sm-Nd isotopic studies were carried out to recognize and define two different groups of geologictectonic terranes of the eastern most part of the "Transversal Zone" (central sub-province) of the Borborema Province, northeast of the South American Platform. The first recognized group (I), formed by granitic orthogneisses and supracrustal rocks is the Alto Pajeú Terrane - APT - that exhibits an isotopic signature with $\mathrm{T}_{\mathrm{DM}}$ values between 2.28 and $1.37 \mathrm{Ga}$, high negative values for $€ \mathrm{Nd}_{(0)}(<-20)$ and with ${ }^{147} \mathrm{Sm} /{ }^{144} \mathrm{Nd}>0.12$ that indicates a possible isotopic fractioning. The second group (II) is composed mostly by orthogneisses (a minor supracrustal belt -Sertânia complex), the Alto Moxotó Terrane -AMT - exhibits an isotopic signature with higher $\mathrm{T}_{\mathrm{DM}}$ values, between 3.0 and $2.0 \mathrm{Ga}$, very negative values for $\mathrm{CNd}$, between -20 and -35 , and ${ }^{147} \mathrm{Sm} /{ }^{144} \mathrm{Nd}$ lower than those of the group I, i.e. between 0.12 and 0.08 . The $\mathrm{CNd}_{(t)}$ values calculated for the assumed ages of both groups are respectively: group I $\mathrm{CNd}_{(950)}=-14$ up to +1.28 ; group II $-\mathrm{CNd}_{(2000)}=-11.28$ up to +1.73 . Additionally, these distinct isotopic patterns worked out as a complementary tool for the geological mapping, as well as, they have gradually been reiterated by means of the study of the Brasiliano granitic plutonism (Ediacaran in age) that occurs piercing both, APT and AMT. Data obtained by other geochronological methods (U-PB and $\mathrm{Rb}-\mathrm{Sr}$ ) for this granites and for the pre-Brasiliano terranes themselves were in good agreement with these above discriminated patterns.
\end{abstract}

Keywords: Sm-Nd isotopic pattern, Borborema Province, Transversal Zone, Alto Pajeú Terrain and Alto Moxotó Terrain.

INTRODUÇÃO A partir da década de 70, com o advento e refinamento das técnicas de análise de isótopos radiogênicos e o aumento expressivo de dados disponíveis, foi possível a utilização da geologia isotópica como ferramenta auxiliar para caracterização de províncias geológicas. Uma província isotópica caracteriza-se pela distribuição homogênea de um padrão isotópico característico (Zartman 1974). O significado geológico dos diferentes padrões de cada isótopo radiogênico pode auxiliar na separação de províncias geológicas em diferentes aspectos: geocronológicos, metalogenéticos e petrológicos.

Pela característica das razões de Sm-Nd serem em grande maioria preservadas dos processos tectonometamórficos, a utilização de isótopos de Nd mostra-se uma ferramenta poderosa para diferenciação de terrenos em áreas poli-metamórfica (Millesenda et al. 1994, Dickin 1998) juntamente com outros métodos geocro- 
nológicos ( $\mathrm{U}-\mathrm{Pb}, \mathrm{Pb}-\mathrm{Pb}, \mathrm{Rb} / \mathrm{Sr}$ ).

Estudos baseados em diferentes métodos geocronológicos (principalmente $\mathrm{U}-\mathrm{Pb}$ e $\mathrm{Sm}-\mathrm{Nd}$ ) têm sido utilizados por diversos autores (Van Schmus et al. 1995, Santos et al. 1999, Brito Neves et al. 2000, Brito Neves et al. 2001 a e b, Santos et al. 2002, Brito Neves et al. 2005 etc) na caracterização dos compartimentos tectônicos que compõem a Província Borborema.

O escopo deste trabalho é integrar os dados geocronológicos $\mathrm{Sm}-\mathrm{Nd}$, $\mathrm{Rb}-\mathrm{Sr}$ e U-Pb já publicados, juntamente com novas análises $\mathrm{Sm}-\mathrm{Nd}$, caracterizando os padrões isotópicos na região limite entre os Terrenos Alto Pajeú e Alto Moxotó. Ambos os terrenos localizamse na Zona Transversal (ZT) da Província Borborema que corresponde a uma megaestrutura situada entre os Lineamentos Patos e Pernambuco (Fig. 1). Apresentam características distintas estruturais, estratigráficas, geocronológicas e geofísicas (Santos et al. 2002). O limite entre estes terrenos caracteriza-se por importantes sistemas de cisalhamento (transcorrentes e de baixo ângulo), que podem ou não representar suturas tectônicas.
MÉTODO O estudo geocronológico, objeto deste trabalho, integra os dados isotópicos ( $\mathrm{Sm}-\mathrm{Nd}, \mathrm{U}-\mathrm{Pb}$ e Rb-Sr) obtidos por Dantas 1996, Fernandes 1997, Almeida 1999, Brito Neves et al. 2001 a e b, Sampaio et al. 2003, Almeida et al. 2002 a e b, Archanjo \& Fetter 2004, Guimarães et al. 2004, Santos et al 2004 e Brito Neves et al. 2005. A estes dados foram somados 20 novas análises $\mathrm{Sm}-\mathrm{Nd}$ realizadas nos laboratórios do Centro de Pesquisas Geocronológicas do Instituto de Geociências da Universidade de São Paulo (CPGeoIGc-USP). Os dados Sm-Nd obtidos e resgatados da literatura estão apresentados na tabela 1.

O presente trabalho concentra-se principalmente na aplicação do método Sm-Nd que é uma importante ferramenta na caracterização de províncias geológicas, pois diferentes tipos litológicos da crosta superior (e.g rochas vulcânicas félsicas e granitóides) exibem razões ${ }^{147} \mathrm{Sm} / \mathrm{Nd}^{144}$ notavelmente constantes, as quais diferem significativamente e consistentemente de sua fonte mantélica pretérita (Millesenda et al. 1994). Esta constância nas razões crustais de Sm-Nd permite a
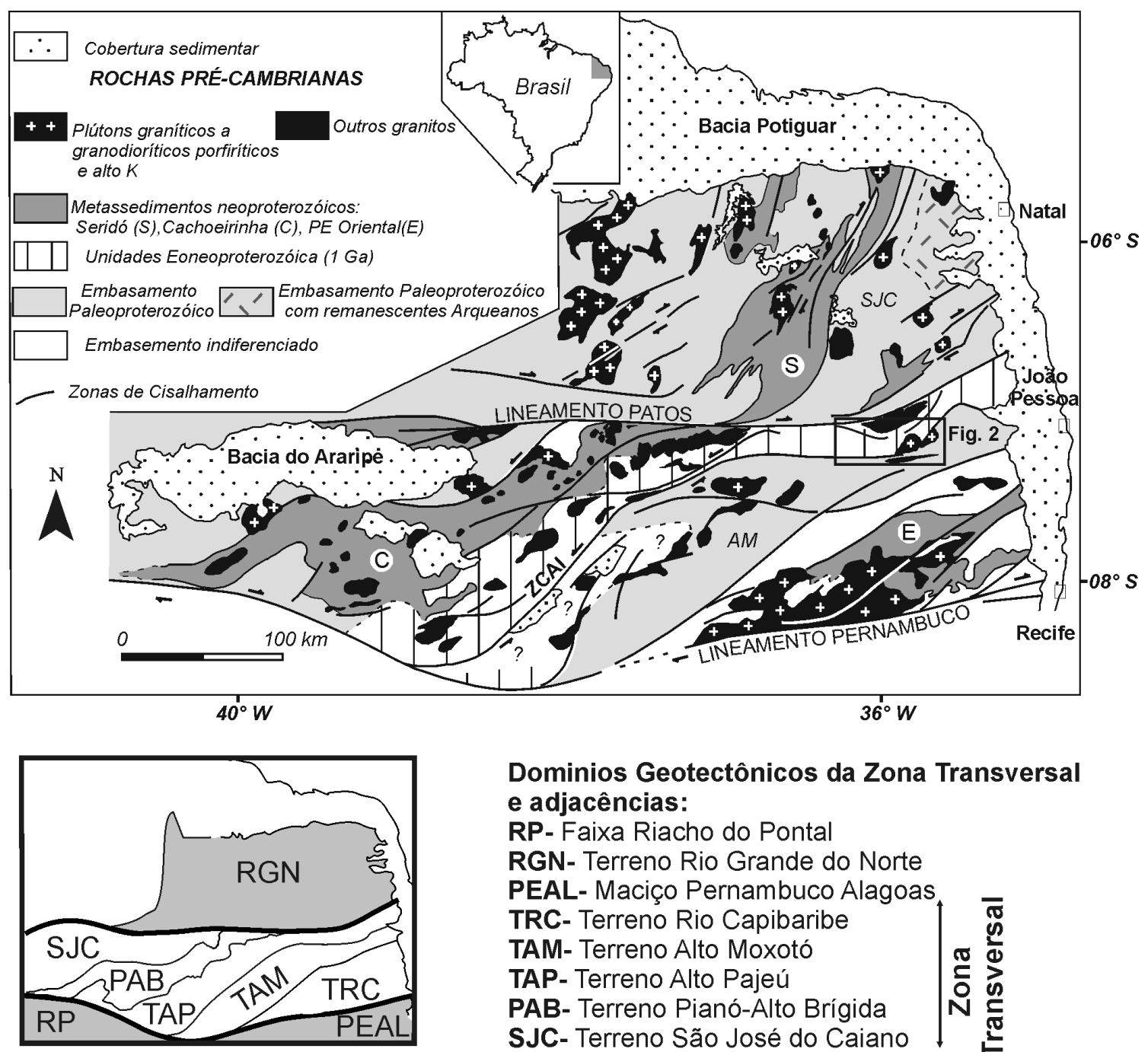

\section{Dominios Geotectônicos da Zona Transversal} e adjacências:

RP- Faixa Riacho do Pontal

RGN- Terreno Rio Grande do Norte

PEAL- Maciço Pernambuco Alagoas

TRC- Terreno Rio Capibaribe

TAM- Terreno Alto Moxotó

TAP- Terreno Alto Pajeú

PAB- Terreno Pianó-Alto Brígida

SJC- Terreno São José do Caiano

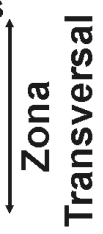

Figura 1 - Contexto geológico e geotectônico regional da Província Borborema (modificado de Archanjo \& Fetter 2004). 
estimação de idades-modelo, relativas à diferenciação manto-crosta $\left(\mathrm{T}_{\mathrm{DM}}\right.$ e $\left.\mathrm{T}_{\mathrm{CHUR}}\right)$, bem como parâmetros petrogenéticos $(\mathrm{CNd})$.

$\mathrm{O}$ parâmetro $\mathrm{CNd}$ corresponde à comparação entre o valor atual ou pretérita da razão ${ }^{143} \mathrm{Nd} /{ }^{144} \mathrm{Nd}$ (atual), com o valor do reservatório condrítico uniforme (CHUR) , calculado pela fórmula (DePaolo 1981, DePaolo 1988) (equação 1):

$$
\mathrm{CNd}_{(\mathrm{T})}=\left[\left({ }^{(143} \mathrm{Nd} /{ }^{144} \mathrm{Nd}\right)_{\operatorname{am}(\mathrm{T})} /\left(\left[\left({ }^{143} \mathrm{Nd} /{ }^{144} \mathrm{Nd}\right)_{\operatorname{chur}(\mathrm{T})}-1\right] \times 10^{4}\right.\right.
$$

$\mathrm{O}$ parâmetro $\epsilon_{\mathrm{Nd}(\mathrm{T})}$ auxilia na identificação das fontes magmáticas magmáticas na formação das rochas. De modo geral o parâmetro $\mathrm{C}_{\mathrm{Nd}(\mathrm{T})}$ quando positivo indica a fonte magmática do $\mathrm{Nd}$ como mantélica, e quanto maior for o seu valor mais empobrecido geoquimicamente é o manto. Quando os valores de $€ \mathrm{Nd}_{(\mathrm{T})}$ apresentam valores negativos a fortemente negativos indicam fontes crustais na formação dos magmas. A progressão para valores fortementes negativos de $\mathrm{CNd}_{(\mathrm{T})}$ é associado ao aumento da participação crustal na formação dos magmas. Por outro lado quando ocorre uma participação de duas fontes (manto ou crosta) os valores de $\mathrm{CNd}$ (T) $\mathrm{em}$ geral flutuam, podendo ser negativo ou positivo, dependendo do grau de participação do material de uma determinada fonte (Sato et al 1995).

$\mathrm{O}$ fato da razão $\mathrm{Sm} / \mathrm{Nd}$ modificar-se significativamente somente durante a diferenciação manto-crosta permite calcular as idade modelos de $\mathrm{Nd}$ (DePaolo 1981 e Sato et al. 1995).

As idades modelo de $\mathrm{Nd}$ são interpretadas como a época no qual uma amostra tinha a mesma composição isotópica em relação a sua fonte, e a partir deste estágio diferenciou-se isotopicamente. A absoluta precisão dessas idades depende do modelo de evolução assumido das fontes mantélicas precursoras das rochas crustais.

As idades modelos são interpretadas a partir da evolução isotópica do Nd baseadas no CHUR (reservatório uniforme condrítico) e DM (manto empobrecido). As idades modelos $\mathrm{T}_{\mathrm{CHUR}}$ e $\mathrm{T}_{\mathrm{DM}}$ de evolução isotópica de Nd segundo o modelo de DePaolo (1981) podem ser calculadas a partir das seguintes equações (equações 2 e 3):

$$
T_{\text {CHUR }}=\frac{1 \ln }{\lambda}\left[1+\frac{\left(\frac{{ }^{143} N d}{{ }^{144} N d}\right)_{C H U R}-\left(\frac{{ }^{143} N d}{{ }^{144} N d}\right)_{A M}}{\left(\frac{{ }^{147} S m}{{ }^{144} N d}\right)_{C H U R}-\left(\frac{{ }^{147} S m}{{ }^{144} N d}\right)_{A M}}\right]
$$

$$
T_{D M}=\frac{1 \ln }{\lambda}\left[1+\frac{\left(\frac{{ }^{143} N d}{{ }^{144} N d}\right)_{D M}-\left(\frac{{ }^{143} N d}{{ }^{144} N d}\right)_{A M}}{\left(\frac{{ }^{147} S m}{{ }^{144} N d}\right)_{D M}-\left(\frac{{ }^{147} S m}{{ }^{144} N d}\right)_{A M}}\right]
$$

As razões isotópicas de $\left({ }^{143} \mathrm{Nd} /{ }^{144} \mathrm{Nd}\right)_{\text {CHUR }} \mathrm{e}_{\text {DM }}$ e $\left({ }^{143} \mathrm{Nd} /{ }^{144} \mathrm{Nd}\right)_{\mathrm{CHUR}} \mathrm{e}_{\mathrm{DM}}$ variam conforme o autor (Jacobsen \& Wasserburg 1984 e Milisenda et al 1994). Neste trabalho é utilizado os seguintes valores para $\left({ }^{143} \mathrm{Nd} /{ }^{144} \mathrm{Nd}\right)_{\mathrm{DM}}=0,513114 \mathrm{e}\left({ }^{143} \mathrm{Nd} /{ }^{144} \mathrm{Nd}\right)_{\mathrm{DM}}=0,222$ (Ben Othman et al. 1984 e Michard et al. 1985) para idades até $2,8 \mathrm{Ga}$, e valores para $\left({ }^{143} \mathrm{Nd} /{ }^{144} \mathrm{Nd}\right)_{\mathrm{DM}}=$ 0,512638 e $\left({ }^{143} \mathrm{Nd} /{ }^{144} \mathrm{Nd}\right)_{\mathrm{DM}}=0,1967$ para idades mais antigas (Ben Othman et al. 1984 e Michard et al. 1985).

Algumas idades modelos de estágio únicos que não apresentam significado podem ser recalculadas a partir do modelo de evolução de estágio duplo que considera o fracionamento entre o $\mathrm{Sm}$ e $\mathrm{Nd}$ na evolução isotópica. O modelo de evolução de estágio duplo de ${ }^{143} \mathrm{Nd} /{ }^{144} \mathrm{Nd}$ em função do tempo geológico pode minimizar os desvios ocasionados por problemas de fracionamento, se forem conhecidas a idade do evento tectono magmático secundário, calculado a partir da isócrona $\mathrm{Sm} / \mathrm{Nd}$ ou por outros métodos como U-Pb em zircões. $\mathrm{O}$ grau de fracionamento adotado para as correções, pode ser estimado com base no valor médio de várias determinações de ${ }^{147} \mathrm{Sm} /{ }^{144} \mathrm{Nd}$, ou por valores teóricos. Este artifício porém não foi utilizado neste trabalho, sendo as idades modelos de estágio único.

CONTEXTO GEOLOGICO REGIONAL A Província Borborema (Fig. 1) é uma ampla região Brasiliana que compreende a região nordeste da Plataforma Sul-Americana. É formada por um sistema ramificado de orógenos neoproterozóicos separados por terrenos proterozóicos e eventualmente por núcleos arqueanos (Brito Neves et al. 2000, Almeida et al. 1981).

$\mathrm{Na}$ região de estudo (Fig. 2) estão presentes quatro importantes terrenos que constituem o arcabouço da Província Borborema, a saber, de norte para sul- Terreno Rio Grande do Norte (RGN) constituído principalmente por rochas paleoproterozóicas que preservaram núcleos arqueanos; Terreno Alto Pajeú (TAP), composto de ortognaisses (Cariris Velhos) e supracrustais (Complexo S. Caetano) de idade Eoneoproterozóicas; Terreno Alto Moxotó (TAM), estruturado por ortognaisses bastante variados, migmatitos e rochas máficas-ultramáficas; Terreno Rio Capibaribe (TRC) composto principalmente por rochas supracrustais xistosas, quartzitos, com intercalações de rochas cálciosilicáticas e carbonáticas. O primeiro destes terrenos (RGN) é representante do domínio setentrional da Borborema, localizado a norte do Lineamento Patos. Os três últimos terrenos são partes integrantes do Domínio da Zona Transversal. Em todos os terrenos citados, na área abordada neste trabalho, ocorrem intrusões graníticas ediacarianas (Complexos graníticos de Esperança, Campina Grande e Queimadas).

Os dois principais terrenos enfatizados neste trabalho são os terrenos Alto Moxotó e Alto Pajeú. As assinaturas aeromagnéticas e de outros sensores geofísicos delimitam domínios com forte contraste magnético e gravimétrico, sendo que os trabalhos de Oliveira \& Santos (1993) e Santos et al. (2002) utilizam estas fer- 
Tabela 1 - Dados Analíticos das determinações Sm-Nd nos domínios e subdomínios isotópicos dos terrenos Alto Pajeú e Alto Moxotó.

\begin{tabular}{|c|c|c|c|c|c|c|c|c|c|c|}
\hline Rocha & Amostra & Coordenadas & $\mathrm{Sm}$ & $\mathrm{Nd}$ & ${ }^{147} \mathrm{Sm} /{ }^{144} \mathrm{Nd}$ & ${ }^{143} \mathrm{Nd} /{ }^{144} \mathrm{Nd}$ & $\operatorname{TDM}(\mathrm{Ga})$ & $\varepsilon N D_{0}$ & $\varepsilon N D_{t}$ & $\mathrm{R}$ \\
\hline \multicolumn{11}{|c|}{ Norte de Esperança $\left(\varepsilon^{2 N D_{(t)}}=2000 \mathrm{Ma}\right)$} \\
\hline Biotita gnaisse & CG-444c & $35^{\circ} 51^{\prime} 17^{\prime \prime} \mathrm{W} 7^{\circ} 03^{\prime} 02^{\prime \prime} \mathrm{S}$ & 3,741 & 20,204 & 0,11198 & 0,51167 & 2,06 & $-18,85$ & 2,76 & \\
\hline Augen gnaisse & esFer & $36^{\circ} 04^{\prime} 04^{\prime \prime} \mathrm{W} 7^{\circ} 05^{\prime} 38^{\prime \prime} \mathrm{S}$ & 5,200 & 27,680 & 0,11360 & 0,51150 & 2,36 & $-22,26$ & $-1,06$ & 7 \\
\hline Biotita gnaisse & esTeo & $36^{\circ} 09^{\prime} 41^{\prime \prime} \mathrm{W} 7^{\circ} 07^{\prime} 07^{\prime \prime} \mathrm{S}$ & 8,290 & 53,560 & 0,09360 & 0,51140 & 2,09 & $-24,21$ & 2,09 & 7 \\
\hline Biotita gnaisse & es134F & $36^{\circ} 07^{\prime} 56^{\prime \prime} \mathrm{W} 7^{\circ} 07^{\prime} 07^{\prime \prime} \mathrm{S}$ & 6,600 & 43,900 & 0,09090 & 0,51138 & 2,06 & $-24,50$ & 2,49 & 7 \\
\hline Migmatito & SCB-Gn-SLG & $35^{\circ} 45^{\prime} 30^{\prime \prime} \mathrm{W} 6^{\circ} 54^{\prime} 50^{\prime \prime} \mathrm{S}$ & 7,154 & 40,956 & 0,10560 & 0,51124 & 2,55 & $-27,19$ & $-3,95$ & 4 \\
\hline \multicolumn{11}{|c|}{ Terreno Alto Pajeú $\left(\varepsilon^{2} D_{(t)}=950\right.$ Ma) } \\
\hline Augen gnaisse & SCB-Agn-59 & $35^{\circ} 39^{\prime} 20^{\prime \prime} \mathrm{W} 7^{\circ} 00^{\prime} 50^{\prime \prime} \mathrm{S}$ & 15,82 & 73,017 & 0,13100 & 0,51208 & 1,77 & $-10,90$ & $-2,94$ & 4 \\
\hline Augen gnaisse & SCB-Agn-61 & $35^{\circ} 39^{\prime} 20^{\prime \prime} \mathrm{W} 7^{\circ} 00^{\prime} 30^{\prime \prime} \mathrm{S}$ & 9,729 & 44,634 & 0,13180 & 0,51202 & 1,90 & $-12,06$ & $-4,19$ & 4 \\
\hline Biot.tite gnaisse & SCB-Mgv-AG & $35^{\circ} 37^{\prime} 40^{\prime \prime} \mathrm{W} 7^{\circ} 02^{\prime} 25^{\prime \prime} \mathrm{S}$ & 5,999 & 28,263 & 0,12830 & 0,51225 & 1,41 & $-7,53$ & 0,76 & 4 \\
\hline Migmatito & SCB-Mi-CG & $35^{\circ} 56^{\prime} 40^{\prime \prime} \mathrm{W} 7^{\circ} 13^{\prime} 20^{\prime \prime} \mathrm{S}$ & 8,56 & 53,23 & 0,09722 & 0,51130 & 2,28 & $-26,20$ & $-14,14$ & 4 \\
\hline Ms-bt-gnaisse & SPP-Gr-LR & $35^{\circ} 51^{\prime} 52^{\prime \prime} \mathrm{W} 7^{\circ} 07^{\prime} 11^{\prime \prime} \mathrm{S}$ & 11,36 & 52,87 & 0,12990 & 0,51213 & 1,66 & $-9,97$ & $-1,87$ & 4 \\
\hline Ms-bt-gnaisse & CG-070 & $35^{\circ} 52^{\prime} 46^{\prime \prime} \mathrm{W} 7^{\circ} 15^{\prime} 34^{\prime \prime} \mathrm{S}$ & 5,896 & 26,908 & 0,13251 & 0,51228 & 1,43 & $-7,03$ & 0,75 & \\
\hline Migmatito & CG-180 & $35^{\circ} 53^{\prime} 38^{\prime \prime} \mathrm{W} 7^{\circ} 11^{\prime} 34^{\prime \prime} \mathrm{S}$ & 8,058 & 32,603 & 0,14945 & 0,51218 & 2,04 & $-8,86$ & $-3,14$ & \\
\hline Mica-xisto & CG-200 & $35^{\circ} 45^{\prime} 38^{\prime \prime} \mathrm{W} 7^{\circ} 07^{\prime} 14^{\prime \prime} \mathrm{S}$ & 3,122 & 12,227 & 0,15440 & 0,51238 & 1,71 & $-5,10$ & 0,03 & \\
\hline Migmatito & CG-411 & $35^{\circ} 58^{\prime} 07^{\prime \prime} \mathrm{W} 7^{\circ} 15^{\prime} 14^{\prime \prime} \mathrm{S}$ & 4,766 & 22,309 & 0,12918 & 0,51228 & 1,37 & $-6,90$ & 1,28 & \\
\hline Mica-xisto & CG-705 & $35^{\circ} 40^{\prime} 55^{\prime \prime} \mathrm{W} 7^{\circ} 04^{\prime} 38^{\prime \prime} \mathrm{S}$ & 3,727 & 15,975 & 0,14106 & 0,51223 & 1,70 & $-7,99$ & $-1,24$ & \\
\hline Ms-bt-gnaisse & SPP-Gr-MJS & $36^{\circ} 01^{\prime} 36^{\prime \prime} \mathrm{W} 7^{\circ} 10^{\prime} 32^{\prime \prime} \mathrm{S}$ & 8,046 & 34,202 & 0,14230 & 0,51217 & 1,86 & $-9,09$ & $-2,50$ & 4 \\
\hline Biotita gnaisse & SC-Mi-45A & $35^{\circ} 36^{\prime} 53^{\prime \prime} \mathrm{W} 7^{\circ} 06^{\prime} 51^{\prime \prime} \mathrm{S}$ & 6,714 & 35,612 & 0,10002 & 0,51197 & 1,64 & $-13,03-$ & $-1,32$ & 4 \\
\hline Biotita gnaisse & SC-Mi-45C & $35^{\circ} 36^{\prime} 53^{\prime \prime} \mathrm{W} 7^{\circ} 06^{\prime} 51^{\prime \prime} \mathrm{S}$ & 12,559 & 70,572 & 0,10760 & 0,51176 & 1,84 & 17,09 & $-6,29$ & 4 \\
\hline \multicolumn{11}{|c|}{ Terreno Alto Moxotó $\left(\varepsilon^{N} D_{(t)}=2000 \mathrm{Ma}\right)$} \\
\hline Biotita gnaisse & SCB-Agn-41c & $35^{\circ} 36^{\prime} 58^{\prime \prime} \mathrm{W} 7^{\circ} 09^{\prime} 14^{\prime \prime} \mathrm{S}$ & 10,995 & 88,731 & 0,07490 & 0,51105 & 2,19 & $-30,92$ & 0,15 & 3 \\
\hline Biotita gnaisse & SCB-Mi-ITB & $35^{\circ} 39^{\prime} 30^{\prime \prime} \mathrm{W} 7^{\circ} 23^{\prime} 30^{\prime \prime} \mathrm{S}$ & 3,11 & 18,930 & 0,09976 & 0,51096 & 2,81 & $-32,73$ & $-8,00$ & 3 \\
\hline Migmatito & SCB-Ag-ITA2 & $35^{\circ} 45^{\prime} 00^{\prime \prime} \mathrm{W} 7^{\circ} 23^{\prime} 00^{\prime \prime} \mathrm{S}$ & 14,74 & 89,415 & 0,09960 & 0,51121 & 2,46 & $-27,84$ & $-3,07$ & 6 \\
\hline Migmatito & SCB-Gn-GAV & $35^{\circ} 57^{\prime} 30^{\prime \prime} \mathrm{W} 7^{\circ} 25^{\prime} 30^{\prime \prime} \mathrm{S}$ & 1,88 & 9,680 & 0,11761 & 0,51161 & 2,29 & $-20,15$ & 0,03 & 3 \\
\hline Biotita gnaisse & SCB-Gn-K44 & $35^{\circ} 31^{\prime} 22^{\prime \prime} \mathrm{W} 7^{\circ} 12^{\prime} 25^{\prime \prime} \mathrm{S}$ & 3,8 & 18,460 & 0,12436 & 0,51141 & 2,81 & $-23,90$ & $-5,44$ & 6 \\
\hline Migmatito & SPP-MI-BJL & $35^{\circ} 49^{\prime} 40^{\prime \prime} \mathrm{W} 7^{\circ} 27^{\prime} 46^{\prime \prime} \mathrm{S}$ & & & 0,11710 & 0,51102 & 3,25 & $-31,56$ & $-11,26$ & 3 \\
\hline Biotita gnaisse & SPP-Gn-PDS & $35^{\circ} 52^{\prime} 03^{\prime \prime} \mathrm{W} 7^{\circ} 27^{\prime} 43^{\prime \prime} \mathrm{S}$ & 3,97 & 27,800 & 0,08644 & 0,51087 & 2,61 & $-34,41$ & $-6,28$ & 6 \\
\hline Biotita gnaisse & SPP-Gn-13 & $35^{\circ} 55^{\prime} 41^{\prime \prime} \mathrm{W} 7^{\circ} 28^{\prime} 10^{\prime \prime} \mathrm{S}$ & 6,035 & 29,326 & 0,12470 & 0,51162 & 2,46 & $-19,96$ & $-1,59$ & 3 \\
\hline Ton. gnaisse & SPP-Gn-SQ & $35^{\circ} 54^{\prime} 36^{\prime \prime} \mathrm{W} 7^{\circ} 26^{\prime} 59^{\prime \prime} \mathrm{S}$ & 0,86 & 4,910 & 0,10649 & 0,51155 & 2,13 & $-21,28$ & 1,73 & 3 \\
\hline Trondj. gnaisse & SPP-Th-NH & $35^{\circ} 54^{\prime} 36^{\prime \prime} \mathrm{W} 7^{\circ} 26^{\prime} 59^{\prime \prime} \mathrm{S}$ & 1,194 & 6,692 & 0,10790 & 0,51141 & 2,37 & $-24,05$ & $-1,40$ & 3 \\
\hline Granito gnaisse & CG-061b & $35^{\circ} 53^{\prime} 55^{\prime \prime} \mathrm{W} 7^{\circ} 20^{\prime} 18^{\prime \prime} \mathrm{S}$ & 4,742 & 33,439 & 0,08576 & 0,51118 & 2,23 & $-28,45$ & $-0,15$ & \\
\hline Granito. gnaisse & CG-170 & $35^{\circ} 54^{\prime} 56^{\prime \prime} \mathrm{W} 7^{\circ} 20^{\prime} 38^{\prime \prime} \mathrm{S}$ & 37,262 & 198,78 & 0,11335 & 0,51202 & 1,55 & $-11,97$ & 9,29 & \\
\hline leucognaisse & CG-360 & $35^{\circ} 49^{\prime} 07^{\prime \prime} \mathrm{W} 7^{\circ} 25^{\prime} 22^{\prime \prime} \mathrm{S}$ & 3,103 & 18,228 & 0,10294 & 0,51118 & 2,58 & $-28,40$ & $-4,48$ & \\
\hline Biotita gnaisse & CG-389 & $35^{\circ} 45^{\prime} 15^{\prime \prime} \mathrm{W} 7^{\circ} 24^{\prime} 58^{\prime \prime} \mathrm{S}$ & 0,421 & 2,412 & 0,10565 & 0,51145 & 2,26 & $-23,20$ & 0,02 & \\
\hline Biotita gnaisse & CG-394 & $35^{\circ} 45^{\prime} 10^{\prime \prime} \mathrm{W} 7^{\circ} 26^{\prime} 46^{\prime \prime} \mathrm{S}$ & 4,255 & 15,267 & 0,16854 & 0,51214 & 3,12 & $-9,64$ & $-2,46$ & \\
\hline leucognaisse & CG-426 & $35^{\circ} 30^{\prime} 46^{\prime \prime} \mathrm{W} 7^{\circ} 17^{\prime} 59^{\prime \prime} \mathrm{S}$ & 9,772 & 19,787 & 0,29862 & 0,51204 & & $-11,64$ & & \\
\hline Biotita gnaisse & CG-427 & $35^{\circ} 29^{\prime} 46^{\prime \prime} \mathrm{W} 7^{\circ} 17^{\prime} 59^{\prime \prime} \mathrm{S}$ & 4,717 & 21,273 & 0,13408 & 0,51168 & 2,63 & $-18,67$ & $-2,69$ & \\
\hline anfibolito & CG-744 & $35^{\circ} 31^{\prime} 00^{\prime \prime} \mathrm{W} 7^{\circ} 14^{\prime} 30^{\prime \prime} \mathrm{S}$ & 5,618 & 34,408 & 0,09874 & 0,51113 & 2,55 & $-29,34$ & $-4,35$ & \\
\hline Granito. gnaisse & CG-752 & $35^{\circ} 33^{\prime} 14^{\prime \prime} \mathrm{W} 7^{\circ} 10^{\prime} 42^{\prime \prime} \mathrm{S}$ & 5,909 & 13,982 & 0,25557 & 0,51200 & & $-12,45$ & & \\
\hline
\end{tabular}

$R=$ referências, 1- Almeida 1999,; 2- Sampaio et al. 2003, 3- Brito Neves et al. 2001b, 4-; Brito Neves et al. 2001a, 5- Fernandes 1997, 6- Dantas,1996, 7- Archanjo \& Fetter, 2004, 8- Guimarães et al. 2004. 
Tabela 1 - Continuação.

\begin{tabular}{|c|c|c|c|c|c|c|c|c|c|c|}
\hline Rocha & Amostra & Coordenadas & $\mathrm{Sm}$ & $\mathrm{Nd}$ & ${ }^{147} \mathrm{Sm} /{ }^{144} \mathrm{Nd}$ & ${ }^{143} \mathrm{Nd} /{ }^{144} \mathrm{Nd}$ & $\mathrm{TDM}(\mathrm{Ga})$ & $\varepsilon \mathrm{ND}_{0}$ & $\varepsilon \mathrm{ND}_{\mathrm{t}}$ & $\mathrm{R}$ \\
\hline \multicolumn{11}{|c|}{ Complexo Sertânia $\left(\mathrm{END}_{(\mathfrak{t})}=2000 \mathrm{Ma}\right)$} \\
\hline Migmatito & CG-005 & $35^{\circ} 38^{\prime} 39^{\prime \prime} \mathrm{W} 7^{\circ} 27^{\prime} 22^{\prime \prime} \mathrm{S}$ & 5,022 & 30,890 & 0,09832 & 0,51113 & 2,55 & $-29,47$ & $-4,37$ & \\
\hline Biotita gnaisse & CG-406 & $35^{\circ} 44^{\prime} 26^{\prime \prime} \mathrm{W} 7^{\circ} 28^{\prime} 07^{\prime \prime} \mathrm{S}$ & 4,921 & 24,771 & 0,12013 & 0,51162 & 2,33 & $-19,95$ & $-0,42$ & \\
\hline Biotita gnaisse & CG-428 & $35^{\circ} 30^{\prime} 27^{\prime \prime} \mathrm{W} 7^{\circ} 22^{\prime} 32^{\prime \prime} \mathrm{S}$ & 3,103 & 16,109 & 0,11650 & 0,51147 & 2,48 & $-22,84$ & $-2,38$ & \\
\hline Sill-bt gnaisse & SPP-Bgx-S & $35^{\circ} 48^{\prime} 48^{\prime \prime} \mathrm{W} 7^{\circ} 29^{\prime} 10^{\prime \prime} \mathrm{S}$ & 13,344 & 91,770 & 0,08790 & 0,51101 & 2,47 & $-31,68$ & $-3,92$ & 3 \\
\hline Biotita gnaisse & SPP-Gn-Col & $35^{\circ} 49^{\prime} 48^{\prime \prime} \mathrm{W} 7^{\circ} 29^{\prime} 10^{\prime \prime} \mathrm{S}$ & 4,269 & 22,233 & 0,11610 & 0,51130 & 2,75 & $-26,12$ & $-5,56$ & 3 \\
\hline Mica-xisto & SPP-Gn-FSL & & 3,116 & 15,576 & 0,12100 & 0,51164 & 2,32 & $-19,53$ & $-0,21$ & 3 \\
\hline Grt-Bt xisto & SPP-Gn-PER & $35^{\circ} 49^{\prime} 16^{\prime \prime} \mathrm{W} 7^{\circ} 30^{\prime} 42^{\prime \prime} \mathrm{S}$ & 10,267 & 46,405 & 0,13380 & 0,51150 & 2,98 & $-22,16$ & $-6,11$ & 3 \\
\hline
\end{tabular}

Terreno Rio Capibaribe $\left(\mathrm{END}_{(\mathrm{t})}=650 \mathrm{Ma}\right)$

\begin{tabular}{l|l|c|c|c|c|c|c|c|c|c}
\hline Biotita gnaisse & CG-003 & $35^{\circ} 38^{\prime} 32^{\prime \prime} \mathrm{W} 7^{\circ} 28^{\prime} 31^{\prime \prime} \mathrm{S}$ & 5,633 & 28,891 & 0,11790 & 0,51209 & 1,52 & $-10,71$ & $-4,18$ & \\
\hline Biotita gnaisse & CG-548 & $35^{\circ} 33^{\prime} 43^{\prime \prime} \mathrm{W} 7^{\circ} 26^{\prime} 06^{\prime \prime} \mathrm{S}$ & 7,111 & 33,329 & 0,12903 & 0,51211 & 1,68 & $-10,39$ & $-4,78$ & \\
\hline Granito & TI-12 & & 49.90 & 8,78 & 0,10640 & 0,51205 & 1,41 & $-11,41$ & $-3,92$ & 8 \\
\hline
\end{tabular}

Complexo Granítico Esperança $\left(\mathrm{END}_{(t)}=580 \mathrm{Ma}\right)$

\begin{tabular}{|c|c|c|c|c|c|c|c|c|c|c|}
\hline Granito & ESP-03A(N) & & 5,96 & 45,55 & 0,07914 & 0,51140 & 1,82 & $-24,13$ & $-15,43$ & 2 \\
\hline Granito & ESP-08A(N & & 4,34 & 31,33 & 0,08371 & 0,51144 & 1,84 & $-23,43$ & $-15,07$ & 2 \\
\hline Granito & ESP-12 (N) & & 4,68 & 27,20 & 0,10409 & 0,51144 & 2,16 & 23,37 & $-16,52$ & 2 \\
\hline Granito & ESP-01(S) & & 6,91 & 39,04 & 0,10708 & 0,51193 & 1,57 & $-13,81$ & $-7,18$ & 2 \\
\hline Granito & PX-01 & & 8,15 & 45,22 & 0,10897 & 0,51200 & 1,50 & $-12,50$ & $-6,01$ & 2 \\
\hline Granito & SCB-GP-ESP & $35^{\circ} 46^{\prime} 31^{\prime \prime} \mathrm{W} 7^{\circ} 04^{\prime} 02^{\prime \prime} \mathrm{S}$ & 4,94 & 31,46 & 0,09491 & 0,51188 & 1,49 & $-14,79$ & $-7,26$ & 4 \\
\hline Granito & Esp-12 & $35^{\circ} 50^{\prime} 30^{\prime \prime} \mathrm{W} 7^{\circ} 04^{\prime} 00^{\prime \prime} \mathrm{S}$ & 3,47 & 26,33 & 0,07980 & 0,51141 & 1,86 & $-23,97$ & $-15,33$ & 7 \\
\hline Tonalite & Es130 & $36^{\circ} 07^{\prime} 56^{\prime \prime \prime} \mathrm{W} 7^{\circ} 07^{\prime} 07^{\prime \prime} \mathrm{S}$ & 6,89 & 35,08 & 0,11870 & 0,51205 & 1,60 & $-11,53$ & $-5,76$ & 7 \\
\hline Granito & Es01 & $36^{\circ} 03^{\prime} 12^{\prime \prime} \mathrm{W} 7^{\circ} 06^{\prime} 19^{\prime \prime} \mathrm{S}$ & 10,63 & 77,38 & 0,08300 & 0,51189 & 1,34 & $-14,57$ & $-6,16$ & 7 \\
\hline
\end{tabular}

Granitos Campina Grande e Serra Redonda $\left(\mathrm{(ND}_{(\mathrm{t})}=580 \mathrm{Ma}\right)$

\begin{tabular}{|c|c|c|c|c|c|c|c|c|c|c|}
\hline Granito & CG-34 & & 116,26 & 17,86 & 0,09280 & 0,51114 & 2,04 & $-29,17$ & $-21,48$ & 8 \\
\hline Granito & NA-26A & & 4,25 & 31,86 & 0,08056 & 0,51146 & 1,81 & $-22,92$ & $-14,33$ & 1 \\
\hline Granodiorito & NA-26B & & 8,53 & 52,94 & 0,09739 & 0,51169 & 1,78 & $-18,57$ & $-11,22$ & 1 \\
\hline Granito & NA-103 & $35^{\circ} 41^{\prime} 39^{\prime \prime} \mathrm{W} 7^{\circ} 14^{\prime} 58^{\prime \prime} \mathrm{S}$ & 7,09 & 50,49 & 0,08495 & 0,51154 & 1,78 & $-21,36$ & $-13,09$ & 1 \\
\hline Granodiorito & NA-98B & & 6,83 & 45,37 & 0,09103 & 0,51161 & 1,78 & $-19,99$ & $-12,18$ & 1 \\
\hline Granito & NA-25 & & 3,59 & 17,95 & 0,12078 & 0,51168 & 1,99 & $-18,61$ & $-12,99$ & 1 \\
\hline Granito & NA-43B & & 6,87 & 55,45 & 0,09667 & 0,51161 & 1,86 & $-19,99$ & $-12,59$ & 1 \\
\hline Granito & SCB-GpSTZ & $35^{\circ} 50^{\prime} 23^{\prime \prime} \mathrm{W} 7^{\circ} 15^{\prime} 04^{\prime \prime} \mathrm{S}$ & 9,12 & 56,66 & 0,09239 & 0,51159 & 1,83 & $-20,44$ & $-12,73$ & 4 \\
\hline
\end{tabular}

\begin{tabular}{|c|c|c|c|c|c|c|c|c|c|c|}
\hline \multicolumn{11}{|c|}{ Granito Queimadas $\left(\mathrm{END}_{(\mathrm{t})}=570 \mathrm{Ma}\right)$} \\
\hline Granito & NA-29 & & 11,21 & 71,66 & 0,09456 & 0,51140 & 2,10 & $-24,07$ & $-16,65$ & 1 \\
\hline Granito & NA-34 & & 17,86 & 116,26 & 0,09288 & 0,51143 & 2,04 & $-23,64$ & $-16,09$ & 1 \\
\hline Granito & NA-107 & & 11,34 & 58,82 & 0,11656 & 0,51184 & 1,89 & $-15,63$ & $-9,80$ & 1 \\
\hline Granito & NA-107C & & 11,13 & 68,14 & 0,09877 & 0,51141 & 2,17 & $-23,99$ & $-16,87$ & 1 \\
\hline Granito & NA-43 & & 58,82 & 11,34 & 0,09290 & 0,51143 & 2,04 & $-23,64$ & $-16,10$ & 1 \\
\hline Granito & SCB-G-QUE & $35^{\circ} 54^{\prime} 16^{\prime \prime} \mathrm{W} 7^{\circ} 20^{\prime} 54^{\prime \prime} \mathrm{S}$ & & & & & 2,17 & $-16,90$ & & 4 \\
\hline
\end{tabular}

$\mathrm{R}=$ referências, 1- Almeida 1999,; 2- Sampaio et al. 2003, 3- Brito Neves et al. 2001b, 4-; Brito Neves et al. 2001a, 5- Fernandes 1997, 6- Dantas,1996, 7- Archanjo \& Fetter, 2004, 8- Guimarães et al. 2004. 

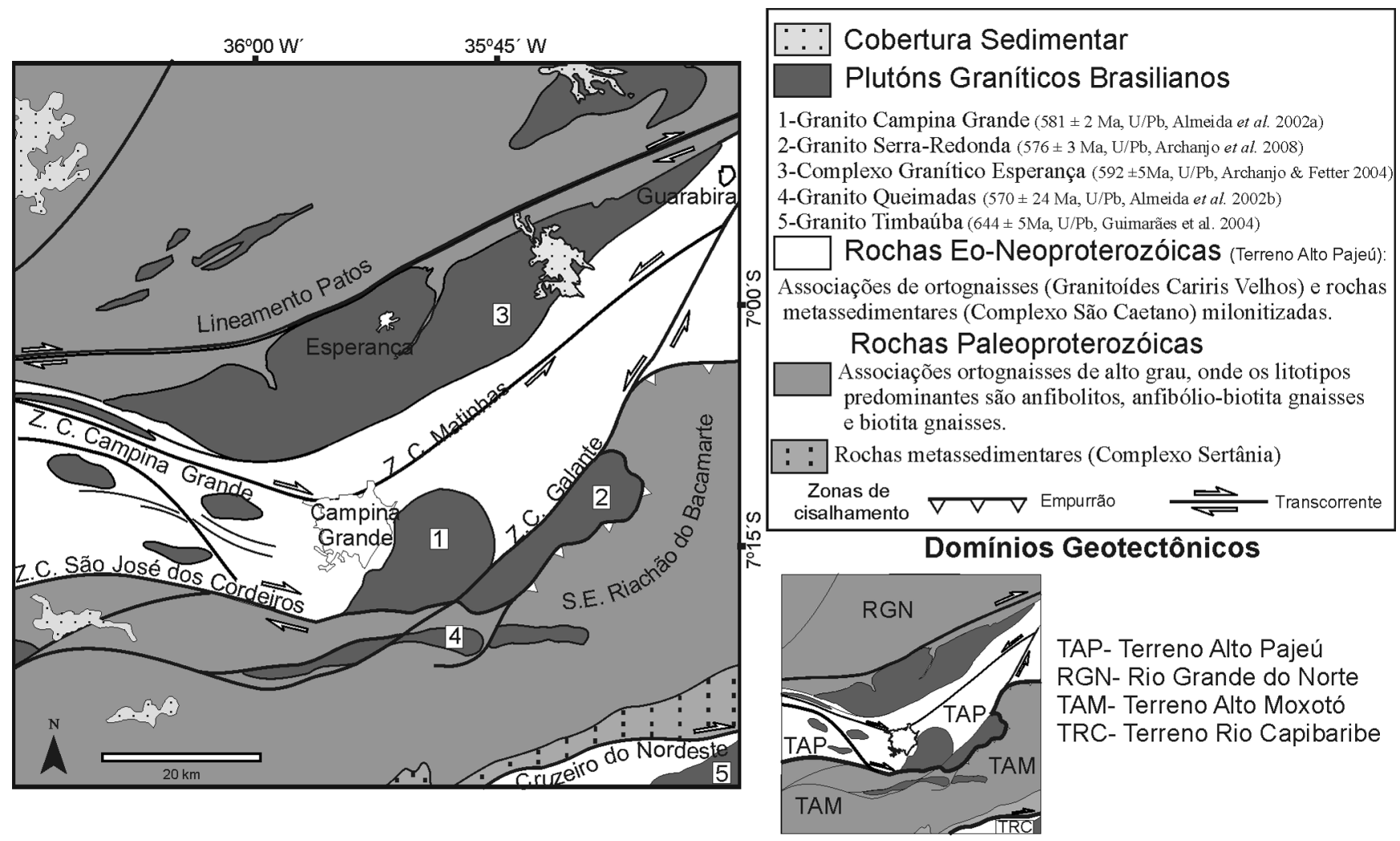

Figura 2 - Mapa esquemático do limite leste dos terrenos Alto Pajeú e Alto Moxotó, enfatizando as principais zonas de cisalhamento e as intrusões graníticas neoproterozóicas.

ramentas para delimitar os limite dos terrenos Alto Moxotó e Alto Pajeú. Conforme já exposto o limite entre estes terrenos caracteriza-se por importantes sistemas de cisalhamento (transcorrentes e de baixo ângulo), que podem ou não representar suturas tectônicas. Santos et al. (2002) associam este limite tectônico com o posicionamento e desenvolvimento da estrutura denominada "Nappe Serra do Jabitacá", que representaria o cavalgamento do TAM sobre o TAP, sendo a idade desta estruturas associada ao "Evento Cariris Velhos" de idade eoneproterozóica. Neste trabalho, este limite tectônico é associado a um sistema de empurrão denominado de "Riachão de Bacamarte", que pode representar a frente de empurrão da "Nappe Serra do Jabitacá". Archanjo et al. 2008 apresenta evidências de que o Sistema de Empurrão de Riachão do Bacamarte foi contemporâneo aos plútons graníticos ediacarianos de Campina Grande e Serra Redonda, influenciando na colocação e na estrutura interna dos mesmos.

Terreno Alto Moxotó (TAM) Santos et al. (2002) apresentam três fatores relevantes na diferenciação do Terreno Alto Moxotó (TAM) dos demais compartimentos do Domínio Transversal: predomínio de rochas paleoproterozóicas, raras intrusões graníticas de idade neoproterozóica e menor influência da deformação associada às grandes zonas de cisalhamento transcorrente regionais. O TAM é limitado a norte com o Terreno Alto Pajeú por zonas de cisalhamento transcorrente regionais e por um sistema de empurrão (Sistema de cavalgamento Riachão do Bacamarte); a sul é limitado pelo Terreno Rio Capibaribe através da Zona de Cisalhamento Congo/Cruzeiro do Norte.

Neste terreno predominam uma série de ortognaisses e paragnaisses aluminosos (Fig. 3). Entres os ortognaisses há litotipos representativos de ortognaisses bandados, ortognaisses graníticos e granodioríticos, anfibolitos, ortognaisses gabro-anortosíticos, migmatitos etc. Os paragnaisses aluminosos constituem a unidade litoestratigráfica denominada de Complexo Sertânia.

Os ortognaisses bandados, anfibolitos e ortognaisses gabro-anortosíticos constituem a principal unidade litoestratigráfica em área do TAM. Estas rochas são intrudidas por uma série de ortognaisses graníticos e granodioríticos. Apresenta uma grande variedade de litotipos, e um retrabalhamento metamórfico e estrutural complexo (Brito Neves et al. 2001b).

O Complexo Sertânia caracteriza-se pela presença de gnaisses aluminosos migmatizados e é composto principalmente por um (granada)-(sillimanita)muscovita-biotita gnaisse de granulação média a fina, textura lepidogranoblástica, equigranular, mesocrático (cor cinza) e com bandamento composicional fino e retilíneo. Apresenta intercalações métricas de anfibolitos, mármores e rochas cálcio-silicáticas.

As determinações geocronológicas do TAM apresentam idades $\mathrm{U} / \mathrm{Pb}$ paleoproterozóicas sendo registradas tantos em zircões magmáticos dos ortognais- 

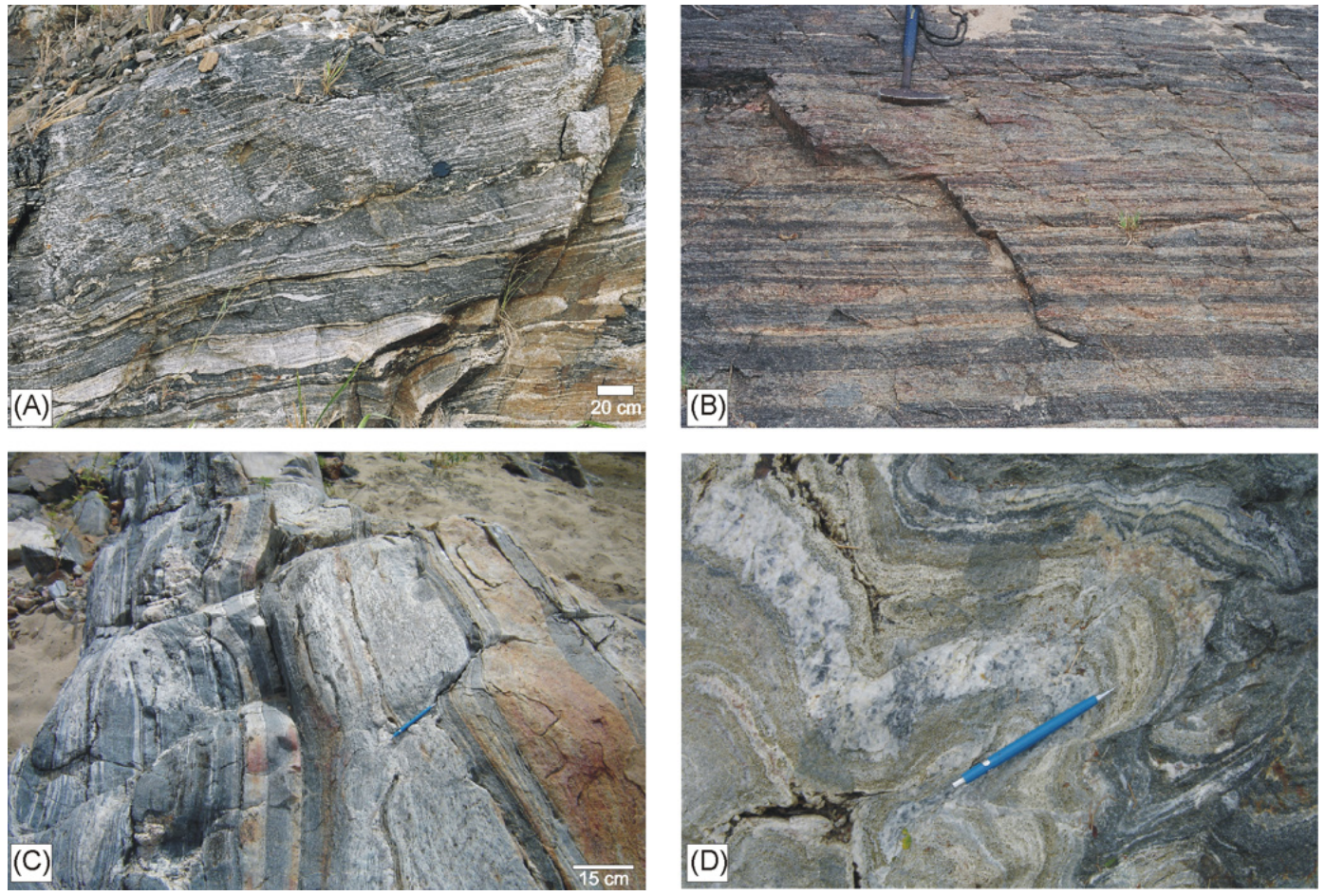

Figura 3 - Fotos dos litotipos associados ao Terreno Alto Moxotó, (A) Ortognaisse bandado: biotita gnaisse bandado, rodovia BR-230, próximo do município de Riachão de Bacamarte, junto ao empurrão homônimo; (B) Anfibolitos e anfibólio- biotita gnaisse bandado (metagabro estratificado?) localizado a $10 \mathrm{~km}$ a sudeste de Itatuba; (C) Migmatito estromático, bandamento centimétrico, alternando níveis de leucossoma (granítico), mesossoma (granodiorítico a granítico) e melanossoma; $5 \mathrm{~km}$ a sul de Itatuba; (D) Camadas de rocha cálcio-silicática alternada com níveis de carbonato e de biotita gnaisse, rocha associada ao Complexo Sertânia, próximo à barragem de Acauã.

ses (idades de $2016 \pm 26 \mathrm{Ma}, 2109 \pm 8,2393 \pm 110 \mathrm{Ma}$, Santos et al. 2004 e Brito Neves et al 2001b), quanto em zircões magmáticos (2126 $\pm 26 \mathrm{Ma}$, Santos et al. 2004) e detríticos ( 2200 a 1950 Ma, Santos et al. 2004) de metavulconoclásticas e metavulcânicas do Complexo Sertânia. Brito Neves et al. 2001b pelo método Rb-Sr também evidência a idade paleoproterozóica pelo alinhamento ao longo da isócrona de referência $2100 \mathrm{Ma}$.

Terreno Alto Pajeú (TAP) O Terreno Alto Pajeú é composto por seqüências de rochas metassedimentares e metavulcanossedimentares e metagranitóides de idades eoneoproterozóicas (Fig. 4). Na região estudada, o limite norte do TAP é balizado pelo Lineamento Patos que o separa do Terreno Rio Grande do Norte (Santos \& Medeiros 1999), a oeste e a sul conforme já mencionado, limita-se com o Terreno Alto Moxotó por zonas de cisalhamento transcorrentes e de empurrão. Adicionalmente ocorrem plútons relacionados ao evento brasiliano (Brito Neves et al. 2003, Guimarães et al. 2002, Ferreira et al. 2004 etc): sin-orogênicos (650-620 Ma), tardi-orogênicos (590-570Ma) e pós-orogênicos (545-520 Ma).

A principal associação vulcano-sedimentar presente no TAP é o Complexo São Caetano caracterizado por Santos et al. (2002) como uma seqüência metassedimentar e metavulcanoclástica dominantemente félsica-intermediária. Os protólitos dos paragnaisses, quartzitos, (granada)- muscovita- biotita gnaisse e mica-xistos são pelitos/psamitos, grauvacas e rochas vulcanoclásticas (Santos 1995).

O TAP na região de estudo apresenta direção E-W/NE-SW devido ao forte controle estrutural das zonas de cisalhamento transcorrente sinistral (Z.C. Matinhas e Z. C. Galante) e destral (Z.C. Campina Grande e São José dos Cordeiros). Estas zonas de cisalhamento delimitam um complexo sistema de estruturas provavelmente consorciadas com a o Lineamento Patos.

O TAP apresenta uma série de datações de idades $\mathrm{U} / \mathrm{Pb}$ eoneoproterozóicas nos ortognaisses graníticos na área estudada (952 $\pm 7 \mathrm{Ma}, 942 \pm 22 \mathrm{Ma}$ e $925 \pm 10 \mathrm{Ma}$, Brito Neves et al. 2001a). Em outras regiões do TAP os ortognaisses graníticos também apresentam este conjunto de idades U/Pb (Brito Neves et al. 1995, Van Schmus 1995, Leite et al. 2000, Brito Neves et al. 2001b, Kozuch 2003). Também no TAP, no Complexo São Caetano também são caracterizadas idades $\mathrm{U} / \mathrm{Pb}$ eoneoproterozóicas em rochas metavulcânicas (980 Ma a 964 Ma, Kozuch 2003) e metavulcanosedimentar (995 \pm 12 Ma, Kozuch 2003).

Granitos intrusivos Na área estudada ocorrem diversos corpos graníticos associados ao evento brasiliano. 

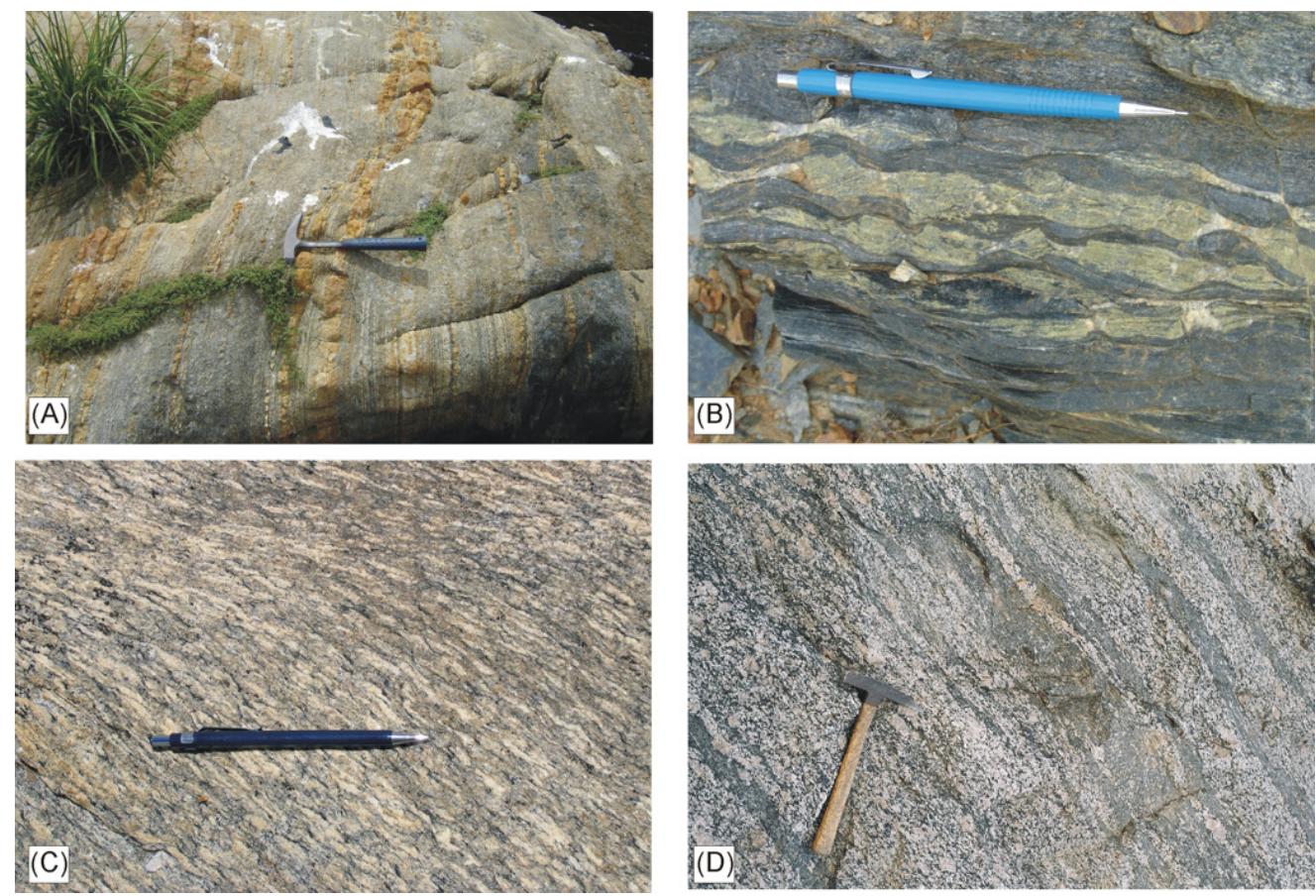

\begin{abstract}
Figura 4 - Fotos dos litotipos associados ao Terreno Alto Pajeú, (A) Muscovita- biotita gnaisse bandado e milonítico, $6 \mathrm{~km}$ a sudoeste de Campina Grande; (B) Camadas centimétricas de níveis anfibolíticos intercalados (cinza escuro) e quartzo-feldspáticos epidotizados, $10 \mathrm{~km}$ a sudoeste de Alagoa Grande; (C) Biotita augen granito gnaisse granítico milonítico com bandas de cisalhamento de caráter sinistral, $2 \mathrm{~km}$ a noroeste de Campina Grande; (D) Anfibólio-biotita granito porfirítico grosso com enclaves microgranulares máficos fortemente alongados e estirados, Granito Campina Grande, 2 km a leste de Campina Grande, rodovia BR-230.
\end{abstract}

O Plúton Queimadas caracterizado no trabalho de Almeida et al. (2002b) constitui uma intrusão tabular alongada E-W intrudida no Terreno Alto Moxotó. Caracteriza-se como uma suíte de biotita- anfibólio monzogranito. É deformado por zonas de cisalhamento de caráter sinistral orientadas E-W, com o desenvolvimento de rochas protomiloníticas a ultramiloníticas. Almeida et al. (2002b) apresenta a idade $\mathrm{U} / \mathrm{Pb}$ de 570 $\mathrm{Ma} \pm 25 \mathrm{Ma}$ para o magmatismo deste plúton.

O Complexo Granítico Esperança (idades U/Pb: $592 \pm 5$ Ma, Archanjo \& Fetter 2004; $581 \pm 3$ Ma, Sampaio et al. 2003) ocorre na porção norte do TAP com direção WSW-ENE e formato sigmoidal. É delimitado a norte pelo Lineamento Patos e a sul pelas Zonas de Cisalhamento Matinhas e Campina Grande. Estão associados a este complexo corpos de anfibólio-biotita granito porfirítico, leucogranito, tonalito e sienogranito (Archanjo \& Fetter 2004).

O Complexo Granítico de Campina Grande assim designado por Almeida et al. (2002a), abrange dois corpos graníticos denominados de Campina Grande e Serra Redonda, situados ao longo do contato TAM e TAP. O Granito Campina Grande (Idade U/Pb $581 \pm$ 2 Ma, Almeida et al. 2002a) destaca-se por sua forma subcircular e arredondada. Já o Granito Serra Redonda (Idade U/Pb $576 \pm 3 \mathrm{Ma}$, Archanjo et al. 2008) apresenta uma estrutura tabular alongada na direção NE-SW. Ambos os corpos graníticos apresentam as mesmas assembléias litológicas principais. A principal em área caracteriza-se por um anfibólio- biotita granito porfirítico; a outra se caracteriza pela presença de dioritos, quartzo-dioritos e granodioritos que, no geral ocorrem nas bordas das intrusões.

O Granito Timbaúba ocorre em uma pequena porção da área estudada situada a sul da Zona de Cisalhamento Congo/Cruzeiro do Nordeste dentro do domínio tectônico do Terreno Rio Capibaribe, encaixado em rochas miloníticas (biotita gnaisse milonítico). Na porção estudada caracteriza-se com um biotita-anfibólio granito porfirítico a fanerítico grosso. Apresenta idade $\mathrm{U} / \mathrm{Pb}$ de $644 \pm 5 \mathrm{Ma}$ (Guimarães et al. 2004).

\section{PADRÕES ISOTÓPICOS DE Nd DA ZONA} TRANSVERSAL (TERRENO ALTO MOXOTÓ $x$ ALTO PAJE Ú) Dentro da abordagem da delimitação de províncias isotópicas pela distribuição homogênea de um padrão isotópico característico, para os terrenos Alto Moxotó e Alto Pajeú são usualmente descritos dois padrões isotópicos de $\mathrm{Nd}$ (Brito Neves et al. 2001a e b, Archanjo \& Fetter. 2004, entre outros). Para o TAM há uma assinatura com idades $\mathrm{T}_{\mathrm{DM}}$ paleoproterozóicas a arqueanas $(2,0$ a $3,0 \mathrm{Ga}), \mathrm{CNd}_{(0)}$ com valores entre $-20,0$ e $-35,0$ e ${ }^{147} \mathrm{Sm} /{ }^{144} \mathrm{Nd}$ concentrada no intervalo de 0,08 e 0,12 . Para o TAP as idades $\mathrm{T}_{\mathrm{DM}}$ são neoproterozóicas a mesoproterozóicas $(1,0$ a $2,0 \mathrm{Ga}), \mathrm{CNd}_{(0)}$ com valores no geral menores que -20 e ${ }^{147} \mathrm{Sm} /{ }^{144} \mathrm{Nd}$ entre 0,10 
e 0,15 . Ressalta-se que os valores ${ }^{147} \mathrm{Sm} /{ }^{144} \mathrm{Nd}$ maiores que 0,12 devem ser utilizados com parcimônia, principalmente quando trata-se de rochas granitóides(que apresentam valores no geral concentrados entre 0,085 a $0,125)$, pois refletem retrabalhamento crustal ou heterogeneidade do reservatório mantélico (Sato 1998).

Os diferentes padrões isotópicos de Nd entre o TAM e o TAP, principalmente em relações as idades $\mathrm{T}_{\mathrm{DM}}$ têm sido utilizados como ferramenta para definir e caracterizar os limites e as áreas de abrangências destes respectivos terrenos (Van Schmus et al., 1995, Brito Neves et al. 2000, Brito Neves et al. 2001a e b, Brito Neves et al. 2005). No entanto, em alguns casos, os valores de idade $\mathrm{T}_{\mathrm{DM}}$ nestes terrenos apresentam valores diferentes aos comumente esperados, e são utilizados para definir subdomínios dentro destes terrenos. Por exemplo, idades $\mathrm{T}_{\mathrm{DM}}$ mais antigas que 2,0 Ga dentro do domínio do TAP, são associados a crosta mais antiga e relacionados com um possível embasamento deste terreno (Brito Neves et al. 2005). No entanto, ressalta-se que alguns aspectos da interpretação dos dados isotópicos de $\mathrm{Nd}$, como fracionamento químico, fonte crustais mistas etc influenciam fortemente nas idades $\mathrm{T}_{\mathrm{DM}}$ causando flutuação de seus valores e podem invalidar a interpretação acima sugerida. Diferentes aspectos da interpretação de dados isotópicos de $\mathrm{Nd}$ são discutidos em inúmeras publicações (Allegre \& Bem Othman 1980, Arndt \& Goldstein 1987, DePaolo 1988 e De Paolo et al. 1991).

$\mathrm{O}$ detalhamento dos dados isotópicos de $\mathrm{Nd}$ no limite entre os TAP e TAM, juntamente com o refinamento da cartografia geológica permitiram identificar e delimitar subdomínios com padrões isotópicos diferenciados. Os dados Sm-Nd foram correlacionados com as seguintes áreas e feições geológicas a saber, de norte para sul: Norte Esperança, que agrega as rochas miloníticas localizada a sul do Lineamento Patos e a norte do Complexo Granítico Esperança; Terreno Alto Pajeú; Terreno Alto Moxotó (sendo diferenciado o Complexo Sertânia) e Terreno Rio Capibaribe.

A plotagem dos dados Sm-Nd do TAM, TAP e dos sub-domínios acima referidos em um gráfico ${ }^{143} \mathrm{Nd} /{ }^{144} \mathrm{Nd} \mathrm{x}{ }^{147} \mathrm{Sm} /{ }^{144} \mathrm{Nd}$ (Fig. 5), apresenta o contraste dos padrões isotópicos observados. No gráfico são definidos a presença de dois padrões isotópicos, aqui informalmente designados de grupos I e II. O Grupo I está associado ao padrão isotópico de $\mathrm{Nd}$ do TAP e TRC, apresenta a distribuição de valores de ${ }^{143} \mathrm{Nd} /{ }^{144} \mathrm{Nd}$ entre 0,5116 a 0,5124 e ${ }^{147} \mathrm{Sm} /{ }^{144} \mathrm{Nd}$ entre 0,10 e 0,15 (com valores no geral maiores que 0,12 ). Conforme já exposto os valores de ${ }^{147} \mathrm{Sm} /{ }^{144} \mathrm{Nd}$ maiores que 0,12 devem ser utilizados com parcimônia, no entanto, indicam o possível fracionamento isotópico como característica relacionada a este grupo.

O padrão isotópico do Grupo II é associado principalmente com as rochas associadas ao TAM (que incluem o Complexo Sertânia), sendo também observado no domínio Norte Esperança. Apresenta a distribuição de valores de ${ }^{143} \mathrm{Nd} /{ }^{144} \mathrm{Nd}$ entre 0,5108 a 0,5116 $\mathrm{e}^{147} \mathrm{Sm} /{ }^{144} \mathrm{Nd}$ entre 0,07 e 0,13 .

A figura 6 apresenta a distribuição das idades
$\mathrm{T}_{\mathrm{DM}}$ e $\mathrm{CNd}_{(0)}$ na área de estudo juntamente com áreas correlatas aos padrões isotópicos dos grupos I e II.

A seguir serão caracterizados os padrões e a evolução isotópica (Fig. 7) dos referidos terrenos e subdomínios.

A área a norte do Complexo Granítico Esperança e sul do Lineamento Patos (Norte Esperança) apresenta uma assinatura isotópica com idades $\mathrm{T}_{\mathrm{DM}}$ paleoproterozóicas, ${ }^{147} \mathrm{Sm} /{ }^{144} \mathrm{Nd}$ entre 0,09 e 0,11 e $\mathrm{CNd}_{(0)}$ com valores $-18,85$ a $-27,19$. O modelamento isotópico de $\mathrm{CNd}_{(2000)}$ para este domínio apresenta valores positivos a fracamente negativos $(2,76 \mathrm{a}-3,95), \mathrm{o}$ que indicaria uma sugerem a contribuição de materiais/ fontes (magmáticas ou sedimentares) juvenis na formação das rochas deste terreno. Este domínio caracterizase por rochas miloníticas situadas a sul do Lineamento Patos, situadas dentro do contexto geotectônico do TAP. No entanto o padrão isotópico deste domínio é contrastante com o observado no TAP, principalmente em relação às idades $\mathrm{T}_{\mathrm{DM}}$. Sua proximidade com as rochas do Terreno Rio Grande do Norte e assinatura isotópica similar a encontrada neste domínio (Van Schmus et al. 1995, Dantas 1996) e no TAM corroboram com a hipótese de associação deste domínio como uma lasca ou relicto de crosta mais antiga dentro do TAP. Esta unidade carece de uma maior investigação geológica e um refinamento da geologia isotópica por outros métodos.

O Terreno Alto Pajeú, na área estudada apresenta uma assinatura isotópica com idades $\mathrm{T}_{\mathrm{DM}}$ variam de 1,37 a $2,28 \mathrm{Ga},{ }^{147} \mathrm{Sm} /{ }^{144} \mathrm{Nd}$ entre 0,09 e 0,15 e $\epsilon \mathrm{Cd}_{(0)}$ com valores $-5,10$ a $-26,20$. O modelamento isotópico de $\mathrm{CNd}_{(950)}$ apresenta uma variação entre 1,28 a -14,14, sendo que há o predomínio de valores fracamente po-

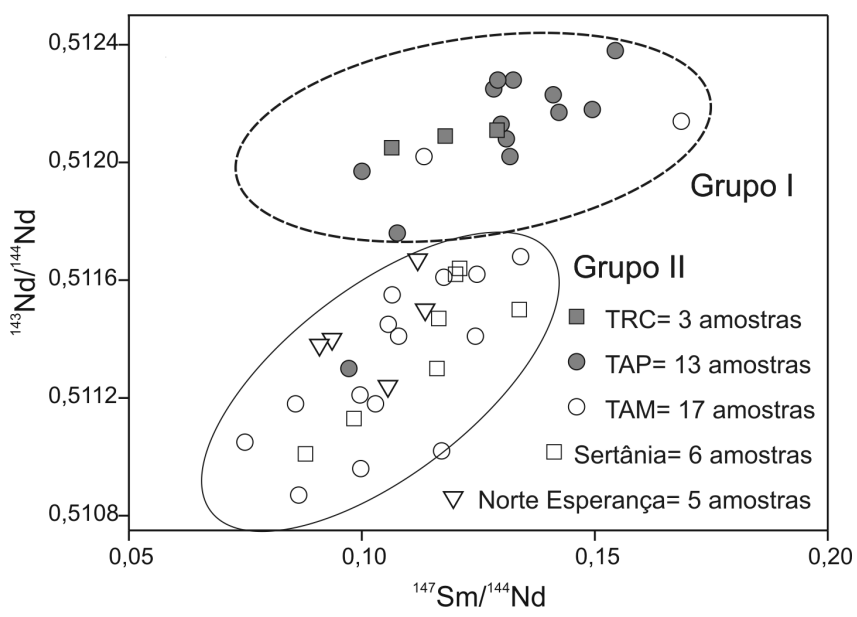

Figura 5 - Gráficos ${ }^{143} \mathrm{Nd} /{ }^{144} \mathrm{Nd} x{ }^{143} \mathrm{Sm} /{ }^{144} \mathrm{Nd}$ para rochas associadas aos terrenos Alto Pajeú (TAP), Rio Capibaribe (TRC), Alto Moxotó (TAM), Complexo Sertânia e as rochas localizadas a sul do Lineamento Patos e norte de Esperança (Norte Esperança). As elipses delimitam agrupamentos de dados que apresentam comportamento isotópico parecido (grupos I e II). 

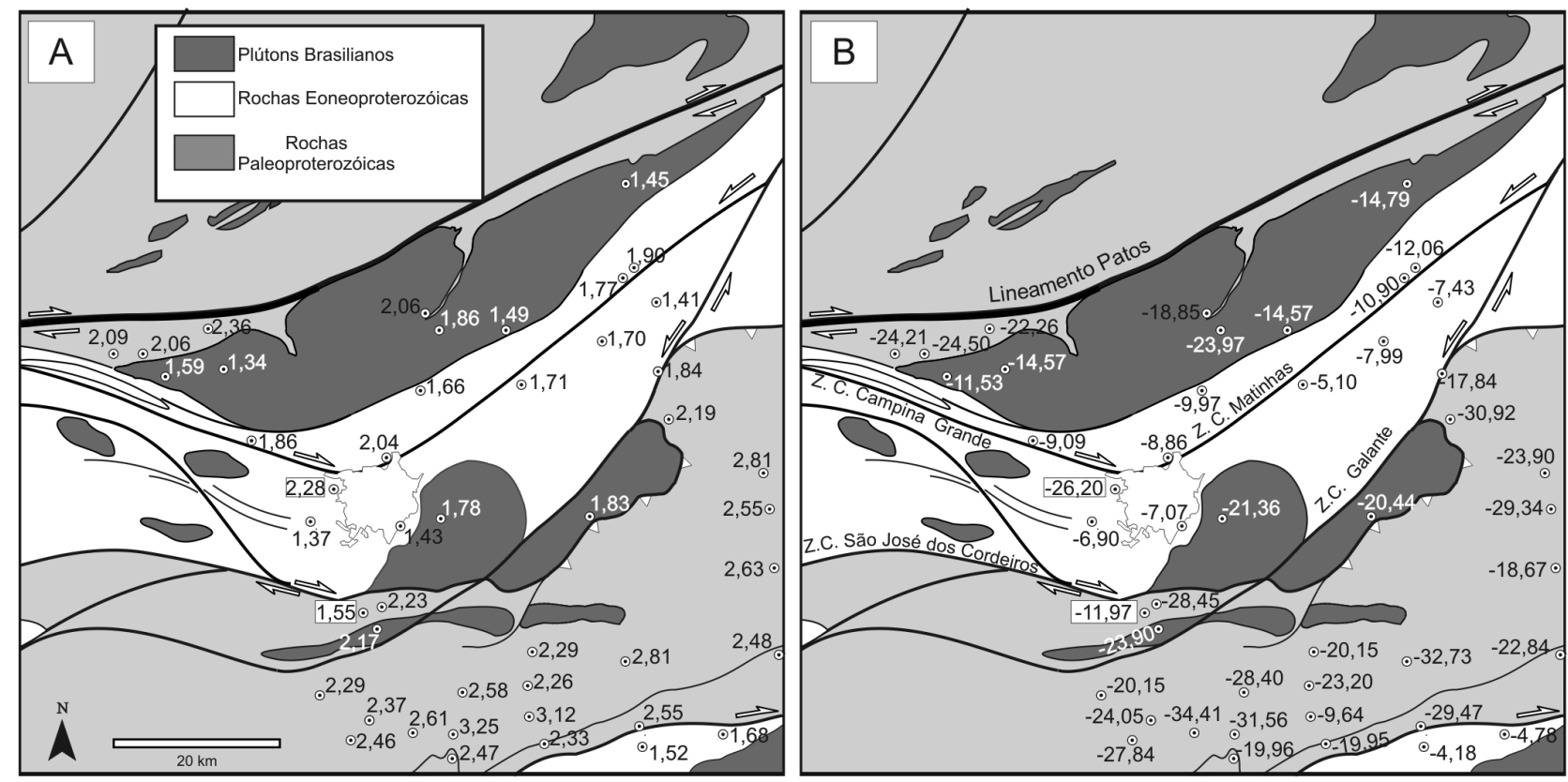

Figura 6 - Distribuição das Idades $T_{D M}(A)$ e $C N d_{(0)}(B)$ na área de estudo. As áreas em brancos são correlatas ao padrão isotópico do Grupo I (Eoneoproterozóico) e as áreas em cinza ao do Grupo II (Paleoproterozóico). Valores anômalos estão apresentados dentro de quadrados. Os valores representativos de corpos graníticos são apresentados em branco.
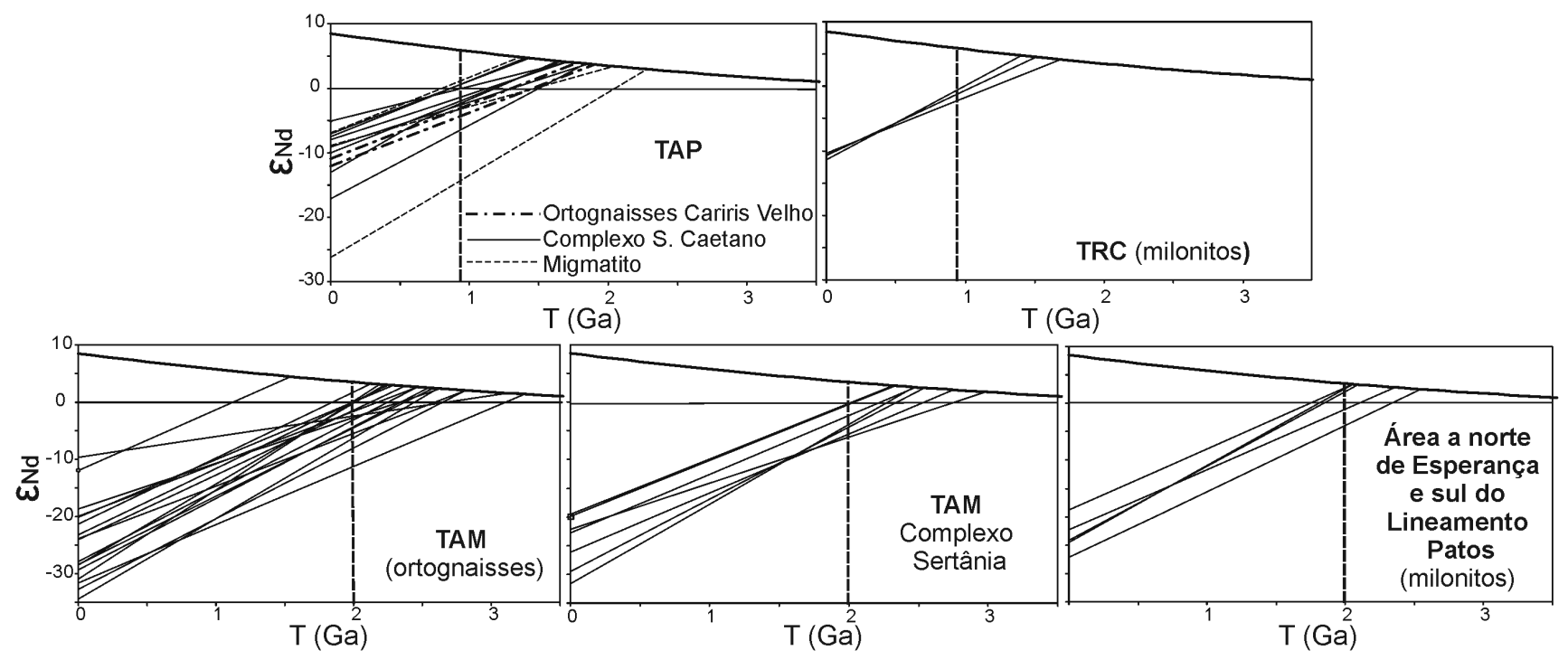

Figura 7 - Diagramas de evolução isotópica de Nd no tempo geológico para as unidades geotectônicas da área de estudo.

sitivos e negativos, o que também sugere a contribuição de materiais/fontes juvenis na formação das rochas deste terreno. Ressalta-se que como há predomínio de valores de ${ }^{147} \mathrm{Sm} /{ }^{144} \mathrm{Nd}$ maiores que 0,12 no TAP, esta interpretação pode ser errônea.

A figura 8 apresenta uma série de dados Sm-Nd das rochas do TAP onde são individualizados os principais litotipos associados a esta unidade: ortognaisses graníticos (Granitóides Cariris Velhos), rochas metasse- dimentares e metavulcanoclástica (Complexo São Caetano) e rochas anômalas (no geral, migmatitos). Os ortognaisses graníticos e rochas metassedimentares apresentam valores de $\mathrm{CNd}_{(\mathrm{t})},{ }^{147} \mathrm{Sm} /{ }^{144} \mathrm{Nd}$ e $\mathrm{T}_{\mathrm{DM}}$ são muito parecidos, o que caracteriza uma assinatura isotópica similar para estas rochas. A similaridade dos padrões isotópicos de $\mathrm{Nd}$ destas rochas, juntamente com as datações isotópicas $\mathrm{U} / \mathrm{Pb}$ (Brito Neves et al. 2001b, Kozuch 2003) evidenciam uma contemporaneidade entre 
a sedimentação, acresção crustal e geração de crosta.

As assinaturas isotópicas $\mathrm{Sm}-\mathrm{Nd}$ relacionadas ao TAP provavelmente refletem um período de acresção crustal relacionado ao "Evento Cariris Velhos" (Brito Neves et al. 1995). Este evento é interpretado por alguns autores como um ciclo orogenético completo, com geração de rochas e metamorfismo (Brito Neves et al. 2001 a), enquanto outros o interpretam com um evento magmático, sendo o metamorfismo de idade brasiliana (Neves et al. 2000, Mariano et al. 2001, Neves 2003). A correlação da assinatura isotópica $\mathrm{Sm}-\mathrm{Nd}$ do TAP com o "Evento Cariris Velhos" é substanciada com as datações $\mathrm{U}-\mathrm{Pb}$. A plotagem dos dados Rb-Sr do TAP em um gráfico ${ }^{87} \mathrm{Rb} /{ }^{86} \mathrm{Sr} x{ }^{87} \mathrm{Sr} /{ }^{86} \mathrm{Sr}$ (Tab. 2, Fig. 9), apresenta um padrão isotópico alinhado a reta de regressão de referência de $950 \mathrm{Ma}$, que possivelmente reflete a homogeneização isotópica do sistema $\mathrm{Rb}-\mathrm{Sr}$ neste período.

Os ortognaisses graníticos (Granitóides Cariris Velhos) são petrograficamente similares aos granitos peraluminosos, pertencendo ao grupo MPG (Muscovite Peraluminous Granites) de Barbarin (1999), que compreende leucogranitos (granitóides félsicos ricos em feldspato potássico e plagioclásio sódico, contendo menos de $5 \%$ e minerais máficos) com muscovita primária, granada e turmalina e com xenólitos das encaixantes nas proximidades dos contatos. Os granitos peraluminosos (MPG) originam-se a partir da fusão de fonte crustais com o aumento da temperatura. $\mathrm{O}$ aumento da temperatura pode ser conseqüência de adelgaçamento crustal, deformação crustal e/ou de fenômenos térmicos locais (e.g., células convectivas). Barbarin (1999) associa este tipo de granito

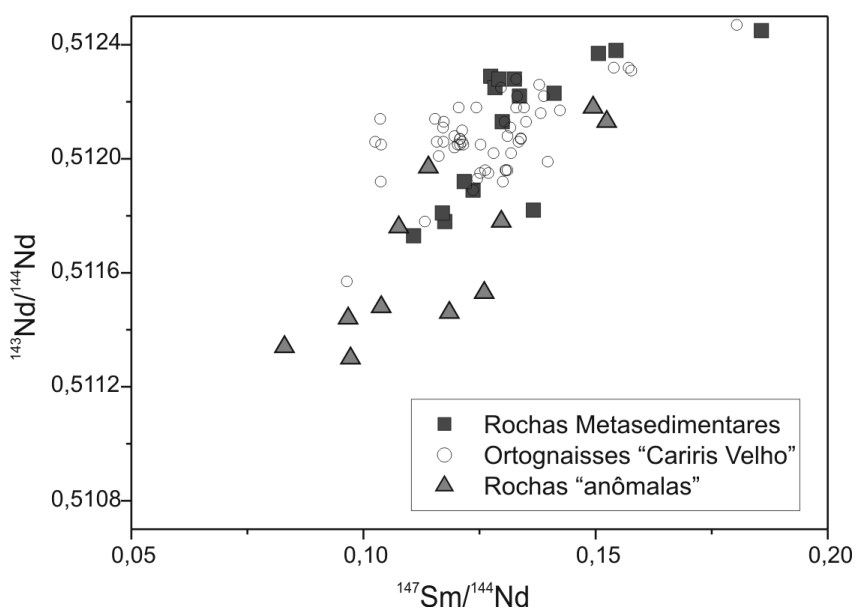

Figura 8 - Gráficos ${ }^{147} \mathrm{Sm} /{ }^{144} \mathrm{Nd} \times{ }^{143} \mathrm{Sm} /{ }^{144} \mathrm{Nd}$ do Terreno Alto Pajeú, separando os litotipos associados: rochas metassedimentares e metavulcanoclástica (Complexo São Caetano) e ortognaisses graníticos (Granitóides Cariris Velhos). Dados referentes aos seguintes trabalhos: Dantas 1996, Fernandes 1997, Almeida 1999, Brito Neves et al. 2001 a e b, Sampaio et al. 2003, Archanjo \& Fetter 2004 e Guimarães et al. 2004.

a orógenos colisionais. A interpretação do tipo e ambiente associado ao magmatismo dos ortognaisses graníticos e das rochas metavulcânicas também não é um consenso nos trabalhos já publicados. Os dados geoquímicos dos

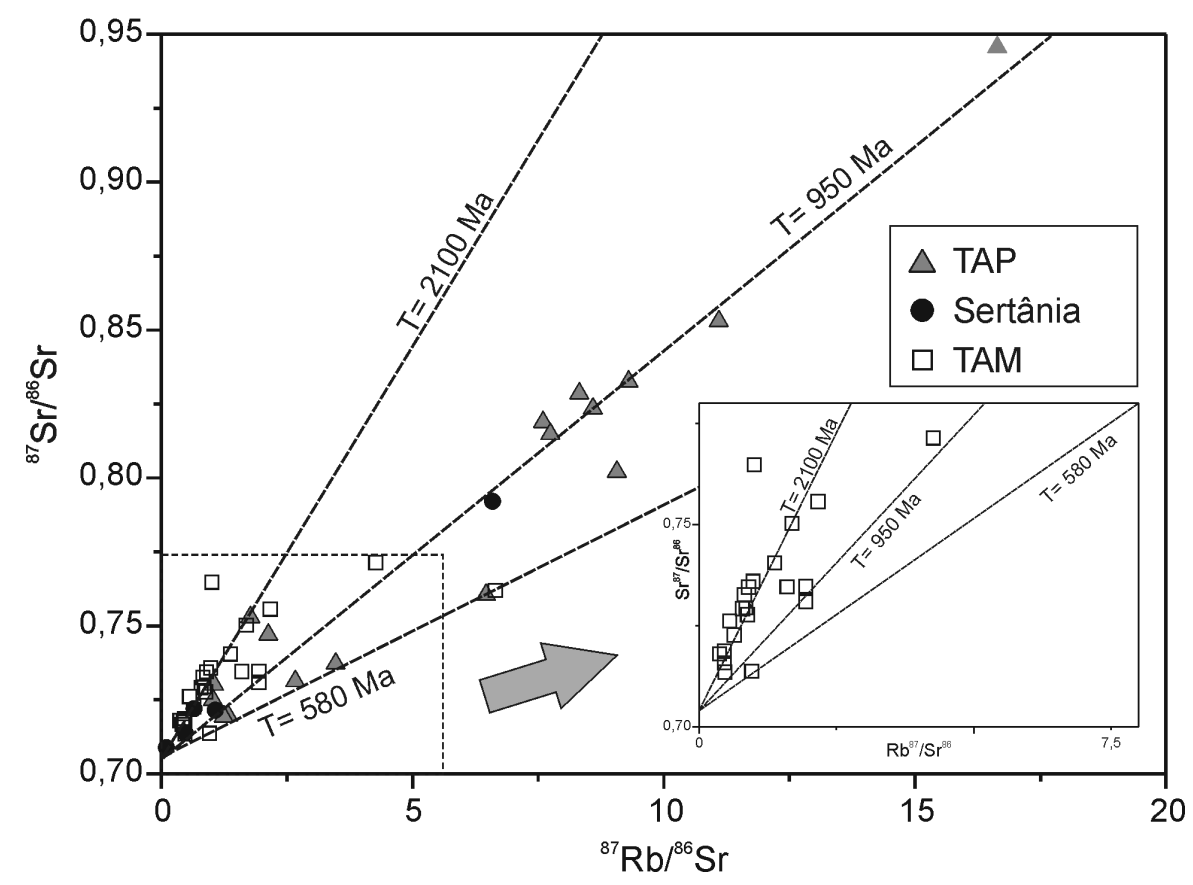

Figura 9 - Gráfico ${ }^{87} \mathrm{Rb}{ }^{86} \mathrm{Sr} x^{87} \mathrm{Sr} /{ }^{86} \mathrm{Sr}$ das rochas associadas aos Terreno Alto Pajeú, Terreno Alto Moxotó e Complexo Sertânia. Retas de regressão para referência de 580, 950 Ma e 2100 Ma. Dados referentes aos seguintes trabalhos: Dantas 1996, Fernandes 1997 e Brito Neves et al. 2001 a e b. 
Tabela 2 - Dados Analíticos das determinações Rb-Sr nos domínios e subdomínios isotópicos dos terrenos Alto Pajeú e Alto Moxotó.

\begin{tabular}{|c|c|c|c|c|c|c|c|}
\hline Rocha & Amostras & Coordenadas & $\mathrm{Rb}$ & $\mathrm{Sr}$ & ${ }^{87} \mathrm{Rb}{ }^{86} \mathrm{Sr}$ & ${ }^{87} \mathrm{Sr} /{ }^{86} \mathrm{Sr}$ & $\mathrm{R}$ \\
\hline \multicolumn{8}{|c|}{ Terreno Alto Pajeú } \\
\hline Augen-gnaisse & SCB-Agn-AgS & $35^{\circ} 37^{\prime} 19^{\prime \prime} \mathrm{W} 7^{\circ} 03^{\prime} 23^{\prime \prime} \mathrm{S}$ & 225,90 & 87,00 & 7,5972 & 0,81889 & 3 \\
\hline Augen-gnaisse & SCB-Agn-59 & $35^{\circ} 40^{\prime} 05^{\prime \prime} \mathrm{W} \quad 7^{\circ} 00^{\prime} 44^{\prime \prime} \mathrm{S}$ & 277,20 & 72,20 & 11,2709 & 0,85304 & 3 \\
\hline Augen-gnaisse & SCB-Agn-61 & $35^{\circ} 39^{\prime} 30^{\prime \prime} \mathrm{W} 7^{\circ} 06^{\prime} 30^{\prime \prime} \mathrm{S}$ & 227,30 & 76,60 & 8,6861 & 0,82348 & 3 \\
\hline Biotita gnaisse & SCB-Gr-PL7 & $35^{\circ} 56^{\prime} 40^{\prime \prime} \mathrm{W} 7^{\circ} 14^{\prime} 45^{\prime \prime} \mathrm{S}$ & 242,10 & 263,50 & 2,6653 & 0,73137 & 3 \\
\hline Ms-bt gnaisse & SPP-Gr-LRO & $35^{\circ} 50^{\prime} 27^{\prime \prime} \mathrm{W} 7^{\circ} 07^{\prime} 59^{\prime \prime} \mathrm{S}$ & 206,39 & 36,20 & 16,8879 & 0,94565 & 3 \\
\hline Augen-gnaisse & SPP-Gr-SJM & $35^{\circ} 57^{\prime} 35^{\prime \prime} \mathrm{W} 7^{\circ} 11^{\prime} 41^{\prime \prime} \mathrm{S}$ & 226,50 & 71,20 & 9,3202 & 0,83260 & 3 \\
\hline Migmatito. & SPP-GR-LUCw & $35^{\circ} 58^{\prime} 07^{\prime \prime} \mathrm{W} 7^{\circ} 15^{\prime} 44^{\prime \prime} \mathrm{S}$ & 259,80 & 212,40 & 3,5504 & 0,73727 & 3 \\
\hline Migmatito. & SPP-GR-LUCb & $35^{\circ} 58^{\prime} 07^{\prime \prime} \mathrm{W} 7^{\circ} 15^{\prime} 44^{\prime \prime} \mathrm{S}$ & 164,90 & 359,30 & 1,3298 & 0,71967 & 3 \\
\hline Mica-xisto & SCB-Mgv-AG & $35^{\circ} 38^{\prime} 07^{\prime \prime} \mathrm{W} 7^{\circ} 01^{\prime} 58^{\prime \prime} \mathrm{S}$ & 443,70 & 199,80 & 6,4606 & 0,76053 & 3 \\
\hline Ms- bt gnaisse & SPP-gr-Pag1 & $36^{\circ} 01^{\prime} 54^{\prime \prime} \mathrm{W} \quad 7^{\circ} 19^{\prime} 23^{\prime \prime} \mathrm{S}$ & 180,10 & 68,00 & 7,7463 & 0,81489 & 3 \\
\hline Ms-bt gnaisse & SPP-gr-Pag2 & $36^{\circ} 01^{\prime} 54^{\prime \prime W} 7^{\circ} 19^{\prime} 23^{\prime \prime} \mathrm{S}$ & 542,10 & 12,20 & 143,855 & 1,91076 & 3 \\
\hline Augen-gnaisse & SCB-Gr-PL1 & $35^{\circ} 57^{\prime} 08^{\prime \prime} \mathrm{W} 7^{\circ} 12^{\prime} 28^{\prime \prime} \mathrm{S}$ & 207,10 & 482,60 & 1,2434 & 0,71930 & 3 \\
\hline Biotita gnaisse & SCB-Gr-PL2 & $35^{\circ} 56^{\prime} 51^{\prime \prime} \mathrm{W} \quad 7^{\circ} 12^{\prime} 50^{\prime \prime} \mathrm{S}$ & 227,30 & 73,20 & 9,0706 & 0,80216 & 3 \\
\hline Biotita gnaisse & SCB-Gr-PL3 & $35^{\circ} 56^{\prime} 42^{\prime \prime} \mathrm{W} 7^{\circ} 13^{\prime} 03^{\prime \prime} \mathrm{S}$ & 174,60 & 336,40 & 1,5055 & 0,73012 & 3 \\
\hline Augen-gnaisse & SCB-Gr-PL4 & $35^{\circ} 56^{\prime} 35^{\prime \prime} \mathrm{W} 7^{\circ} 13^{\prime} 20^{\prime \prime} \mathrm{S}$ & 102,10 & 139,30 & 2,1295 & 0,74708 & 3 \\
\hline Biotita gnaisse & SCB-Gr-PL5 & $35^{\circ} 56^{\prime} 31^{\prime \prime} \mathrm{W} 7^{\circ} 13^{\prime} 59^{\prime \prime} \mathrm{S}$ & 130,90 & 221,30 & 1,7196 & 0,75296 & 3 \\
\hline Biotita gnaisse & SCB-Gn-45A & $35^{\circ} 36^{\prime} 53^{\prime \prime} \mathrm{W} \quad 7^{\circ} 06^{\prime} 51^{\prime \prime} \mathrm{S}$ & 234,90 & 82,70 & 8,3185 & 0,82860 & 3 \\
\hline Biotita gnaisse & SCB-Mi45A & $35^{\circ} 36^{\prime} 53^{\prime \prime} \mathrm{W} 7^{\circ} 06^{\prime} 51^{\prime \prime} \mathrm{S}$ & 104,80 & 295,30 & 1,0289 & 0,72497 & 3 \\
\hline Biotita gnaisse & SCB-Mi45B & $35^{\circ} 36^{\prime} 53^{\prime \prime} \mathrm{W} \quad 7^{\circ} 06^{\prime} 51^{\prime \prime} \mathrm{S}$ & 234,90 & 82,70 & 8,3186 & 0,82860 & 3 \\
\hline \multicolumn{8}{|c|}{ Terreno Alto Moxotó } \\
\hline Migmatito & SPP-Mi-BJLM & $35^{\circ} 49^{\prime} 40^{\prime \prime} \mathrm{W} \quad 7^{\circ} 27^{\prime} 46^{\prime \prime} \mathrm{S}$ & 125,60 & 265,10 & 1,3756 & 0,74047 & 4 \\
\hline Migmatito & SPP-Gn-13 & $35^{\circ} 54^{\prime} 16^{\prime \prime} \mathrm{W} 70^{\circ} 20^{\prime} 54^{\prime \prime} \mathrm{S}$ & 41,00 & 259,00 & 0,4585 & 0,71577 & 4 \\
\hline Biotita gnaisse & SCB-Agn-ITA & $35^{\circ} 39^{\prime} 04^{\prime \prime} \mathrm{W} \quad 7^{\circ} 22^{\prime} 46^{\prime \prime} \mathrm{S}$ & 142,40 & 212,00 & 1,9484 & 0,73085 & 4 \\
\hline Migmatito & TM 24A & $35^{\circ} 37^{\prime} 02^{\prime \prime} \mathrm{W} 7^{\circ} 19^{\prime} 50^{\prime \prime} \mathrm{S}$ & 89,00 & 433,40 & 0,5954 & 0,72613 & 5 \\
\hline Migmatito. & TM 24B & $35^{\circ} 37^{\prime} 02^{\prime \prime} \mathrm{W} 7^{\circ} 19^{\prime} 50^{\prime \prime} \mathrm{S}$ & 84,50 & 297,20 & 0,8249 & 0,73260 & 5 \\
\hline Migmatito. & TM24C & $35^{\circ} 37^{\prime} 02^{\prime \prime} \mathrm{W} 7^{\circ} 19^{\prime} 50^{\prime \prime} \mathrm{S}$ & 94,20 & 304,10 & 0,8989 & 0,73453 & 5 \\
\hline Biotita gnaisse & TM77A & $35^{\circ} 35^{\prime} 40^{\prime \prime} \mathrm{W} 7^{\circ} 17^{\prime} 44^{\prime \prime} \mathrm{S}$ & 162,30 & 279,30 & 1,6889 & 0,75029 & 5 \\
\hline Biotita gnaisse & TM 77B & $35^{\circ} 35^{\prime} 40^{\prime \prime} \mathrm{W} 7^{\circ} 17^{\prime} 44^{\prime \prime} \mathrm{S}$ & 92,90 & 642,50 & 0,4188 & 0,71671 & 5 \\
\hline Migmatito & GT-C-16 & $35^{\circ} 33^{\prime} 59^{\prime \prime} \mathrm{W} \quad 7^{\circ} 18^{\prime} 20^{\prime \prime} \mathrm{S}$ & 93,60 & 591,00 & 0,4589 & 0,71870 & 5 \\
\hline Migmatito & GT-C-18 & $35^{\circ} 33^{\prime} 59^{\prime \prime} \mathrm{W} \quad 7^{\circ} 18^{\prime} 20^{\prime \prime} \mathrm{S}$ & 207,40 & 311,10 & 1,9315 & 0,71870 & 3 \\
\hline Migmatito & GT-C-19 & $35^{\circ} 33^{\prime} 59^{\prime \prime} \mathrm{W} \quad 7^{\circ} 18^{\prime} 20^{\prime \prime} \mathrm{S}$ & 175,10 & 317,50 & 1,5979 & 0,71870 & 3 \\
\hline Biotita gnaisse & TM-254B & $35^{\circ} 24^{\prime} 44^{\prime \prime} \mathrm{W} \quad 7^{\circ} 15^{\prime} 27^{\prime \prime} \mathrm{S}$ & 22,70 & 97,60 & 0,6739 & 0,71870 & 5 \\
\hline Biotita gnaisse & TM-254C & $35^{\circ} 24^{\prime} 44^{\prime \prime} \mathrm{W} \quad 7^{\circ} 15^{\prime} 27^{\prime \prime} \mathrm{S}$ & 111,28 & 688,54 & 0,4683 & 0,71870 & 5 \\
\hline Biotita gnaisse & TM-254A & $35^{\circ} 24^{\prime} 44^{\prime \prime} \mathrm{W} \quad 7^{\circ} 15^{\prime} 27^{\prime \prime} \mathrm{S}$ & 200,80 & 87,90 & 6,6186 & 0,71870 & 5 \\
\hline Migmatito & GT-C-15 & $35^{\circ} 33^{\prime} 59^{\prime \prime} \mathrm{W} 7^{\circ} 07^{\prime} 59^{\prime \prime} \mathrm{S}$ & 93,60 & 591,00 & 0,4589 & 0,71870 & 3 \\
\hline Biotita gnaisse & SCB-Mi-CG43 & $35^{\circ} 34^{\prime} 38^{\prime \prime} \mathrm{W} 7^{\circ} 08^{\prime} 12^{\prime \prime} \mathrm{S}$ & 258,30 & 162,70 & 4,6236 & 0,77136 & 4 \\
\hline Biotita gnaisse & SCB-Agn-41c & $35^{\circ} 36^{\prime} 29^{\prime \prime} \mathrm{W} \quad 7^{\circ} 09^{\prime} 14^{\prime \prime} \mathrm{S}$ & 151,10 & 457,50 & 0,9564 & 0,71369 & 4 \\
\hline Biotita gnaisse & $\mathrm{B}-11-2 \mathrm{R}$ & $35^{\circ} 35^{\prime} 22^{\prime \prime} \mathrm{W} \quad 7^{\circ} 12^{\prime} 25^{\prime \prime} \mathrm{S}$ & 48,20 & 381,50 & 0,3660 & 0,71800 & 3 \\
\hline Biotita gnaisse & $\mathrm{B}-11-2 \mathrm{~T}$ & $35^{\circ} 35^{\prime} 22^{\prime \prime} \mathrm{W} 7^{\circ} 12^{\prime} 25^{\prime \prime} \mathrm{S}$ & 69,20 & 453,90 & 0,4417 & 0,71750 & 3 \\
\hline Biotita gnaisse & SPP-B-1 & $35^{\circ} 52^{\prime} 11^{\prime \prime} \mathrm{W} 7^{\circ} 27^{\prime} 41^{\prime \prime} \mathrm{S}$ & 105,80 & 314,20 & 0,9772 & 0,73580 & 3 \\
\hline Biotita gnaisse & SPP-B-2 & $35^{\circ} 52^{\prime} 11^{\prime \prime W} 7^{\circ} 27^{\prime} 41^{\prime \prime} \mathrm{S}$ & 114,30 & 380,00 & 0,8723 & 0,72770 & 3 \\
\hline Biotita gnaisse & SPP-B-3 & $35^{\circ} 52^{\prime} 11^{\prime \prime} \mathrm{W} 7^{\circ} 27^{\prime} 41^{\prime \prime} \mathrm{S}$ & 84,60 & 385,80 & 0,6356 & 0,72270 & 3 \\
\hline Biotita gnaisse & SPP-B-4 & $35^{\circ} 52^{\prime} 11^{\prime \prime} \mathrm{W} 7^{\circ} 27^{\prime} 41^{\prime \prime} \mathrm{S}$ & 96,70 & 353,20 & 0,7941 & 0,72920 & 3 \\
\hline Biotita gnaisse & SPP-B-5 & $35^{\circ} 52^{\prime} 11^{\prime \prime} \mathrm{W} 77^{\circ} 27^{\prime} 41^{\prime \prime} \mathrm{S}$ & 101,50 & 345,90 & 0,8511 & 0,72940 & 3 \\
\hline Migmatito. & SPP-Mi-BJL & $35^{\circ} 49^{\prime} 40^{\prime \prime} \mathrm{W} \quad 7^{\circ} 27^{\prime} 46^{\prime \prime} \mathrm{S}$ & 61,40 & 177,70 & 1,0056 & 0,76483 & 4 \\
\hline
\end{tabular}

R=Referências: 1- Almeida 1999, 2- Sampaio et al. 2003, 3-Brito Neves et al. 2001b, 4-Brito Neves et al. 2001a, 5- Fernandes 1997, 6- Dantas1996, 7- Archanjo \& Fetter 2004, 8- Guimarães et al. 2004. 
Tabela 2 - Continuação.

\begin{tabular}{|c|c|c|c|c|c|c|c|}
\hline Rocha & Amostra & Coordenadas & $\mathrm{Rb}$ & $\mathrm{Sr}$ & ${ }^{87} \mathrm{Rb} /{ }^{86} \mathrm{Sr}$ & ${ }^{87} \mathrm{Sr} /{ }^{86} \mathrm{Sr}$ & $\mathrm{R}$ \\
\hline \multicolumn{8}{|c|}{ Complexo Sertânia } \\
\hline Biotita gnaisse & SPP-A-20 & $35^{\circ} 28^{\prime} 38^{\prime \prime} \mathrm{W} 7^{\circ} 21^{\prime} 56^{\prime \prime} \mathrm{S}$ & 109,30 & 295,00 & 1,0738 & 0,72150 & 3 \\
\hline Migmatito. & SPP-A-23 & $35^{\circ} 31^{\prime} 46^{\prime \prime} \mathrm{W} 7^{\circ} 23^{\prime} 45^{\prime \prime} \mathrm{S}$ & 69,30 & 475,60 & 0,4220 & 0,71400 & 3 \\
\hline Migmatito. & SPP-A-28 & $35^{\circ} 32^{\prime} 30^{\prime \prime} \mathrm{W} 7^{\circ} 25^{\prime} 34^{\prime \prime} \mathrm{S}$ & 277,00 & 122,70 & 6,5881 & 0,79210 & 3 \\
\hline Biotita gnaisse & SPP-Gn-Ccol & $35^{\circ} 49^{\prime} 48^{\prime \prime} \mathrm{W} 7^{\circ} 29^{\prime} 01^{\prime \prime} \mathrm{S}$ & 104,00 & 467,10 & 0,6453 & 0,72200 & 3 \\
\hline Biotita gnaisse & SPP-gn-WSSF & $35^{\circ} 31^{\prime} 37^{\prime \prime} \mathrm{W} 7^{\circ} 26^{\prime} 23^{\prime \prime} \mathrm{S}$ & 5,00 & 148,00 & 0,0978 & 0,70892 & 3 \\
\hline \multicolumn{8}{|c|}{ Granito Esperança } \\
\hline Granito & ESP-03a & & 148,00 & 1194,00 & 0,3588 & 0,70896 & 2 \\
\hline Granito & ESP-08a & & 125,00 & 989,00 & 0,3659 & 0,70938 & 2 \\
\hline Granito & ESP-08b & & 230,00 & 1010,00 & 0,6591 & 0,70869 & 2 \\
\hline Granito & ESP-12 & & 85,00 & 838,00 & 0,2936 & 0,71063 & 2 \\
\hline Granito & PX-01 & & 164,20 & 283,40 & 1,6790 & 0,72092 & 2 \\
\hline \multicolumn{8}{|c|}{ Granitos Campina Grande e Serra Redonda } \\
\hline Granito & NA-26A & & 152,00 & 385,00 & 1,1419 & 0,71733 & 1 \\
\hline Granodiorito & NA-26B & & 93,00 & 1012,00 & 0,2659 & 0,70705 & 1 \\
\hline Granito & NA-98A & & & 149,00 & & 0,70699 & 1 \\
\hline Granito & NA-103 & $35^{\circ} 41^{\prime} 39^{\prime \prime} \mathrm{W} 7^{\circ} 14^{\prime} 58^{\prime \prime} \mathrm{S}$ & 117,00 & 745,00 & 0,4545 & 0,70681 & 1 \\
\hline Granito & NA-104 & & & 338,00 & & 0,71134 & 1 \\
\hline Basalto & NA-12A & & 10,00 & 347,00 & 0,0834 & 0,70420 & 1 \\
\hline Granodiorito & NA-98B & & 167,00 & 926,00 & 0,5219 & 0,70694 & 1 \\
\hline Granito & NA-25 & & 44,00 & 735,00 & 0,1732 & 0,70610 & 1 \\
\hline Granodiorito & NA-43B & & 80,00 & 1015,00 & 0,2281 & 0,70919 & 1 \\
\hline \multicolumn{8}{|c|}{ Granito Queimadas } \\
\hline Granito & NA-91 & & 223,00 & 136,00 & 4,7631 & 0,74519 & 1 \\
\hline Granito & NA-107B & & 174,00 & 121,00 & 4,1746 & 0,73864 & 1 \\
\hline Granito & NA-29 & & 170,00 & 185,00 & 2,6653 & 0,72970 & 1 \\
\hline Granito & NA-34 & & 145,00 & 200,00 & 2,1023 & 0,72739 & 1 \\
\hline Granito & GT-6-10 & & 176,30 & 198,40 & 2,5771 & 0,72880 & 3 \\
\hline
\end{tabular}

R=Referências: 1- Almeida 1999, 2- Sampaio et al. 2003, 3- Brito Neves et al. 2001b, 4- Brito Neves et al. 2001a, 5- Fernandes 1997, 6- Dantas1996, 7- Archanjo \& Fetter 2004, 8- Guimarães et al. 2004.

ortognaisses graníticos são correlacionados com diferentes ambientes tectônicos conforme o modelo interpretativo utilizado. Brito Neves et al. (2003) associam o magmatismo a ambientes similares ao de granitóides colisionais, enquanto Guimarães \& Brito Neves (2005) a de granitos aluminosos do tipo-A. A presença de valores maiores que $0,12 \mathrm{de}^{147} \mathrm{Sm} /{ }^{144} \mathrm{Nd}$ representa um alerta para a interpretações geocronológicas, geoquímicas e ambientes tectônicos das rochas do TAP. Conforme já exposto, os valores maiores que $0,12 \mathrm{de}{ }^{147} \mathrm{Sm} /{ }^{144} \mathrm{Nd}$ nas rochas graníticas indicam fracionamento isotópico do $\mathrm{Nd}$, e também possivelmente de outros elementos químicos, que poderiam gerar assinaturas geoquímicas e isotópicas anômalas.

O "Evento Cariris Velhos" denota para um período de acresção crustal e de intenso magmatismo associado. Sua eventual deformação e metamorfismos contemporâneos aos eventos magmáticos, no entanto, na área estudada não apresentam vestígios claros ou definidos. Na região de estudo a intensa deformação (principalmente de caráter milonítico) observada nos ortognaisses graníticos (Granitóides Cariris Velhos) é essencialmente associada com estruturação das grandes zonas de cisalhamento regionais transcorrente e de baixo ângulo desenvolvidas no evento brasiliano e que 
também controlam o alojamento dos granitos intrusivos no TAP. Os plútons graníticos de Esperança e de Serra Redonda registram especificamente a deformação associada a estruturas associadas a empurrões (Archanjo \& Fetter 2004 e Archanjo et al. 2008) enquanto os plútons graníticos de Queimadas e Campina Grande registram a deformação associada a transcorrências (Archanjo et al. 2008). Os empurrões e as transcorrências são compatíveis com esforços compressivos de direção NNWSSE que possivelmente atuaram conjuntamente com os eventos magmáticos associados aos plútons ediacarianos. Deste modo a deformação registrada nos ortognaisses possivelmente está associada ao evento brasiliano, tendo como idade de referência as datações U-Pb dos granitos intrusivos no TAM e TAP (570 a $590 \mathrm{Ma})$.

O Terreno Alto Moxotó (TAM) apresenta idades $\mathrm{T}_{\mathrm{DM}}$ paleoproterozóicas a arqueanas $(2,0$ a 3,0 Ga), $\mathrm{CNd}_{(0)}$ com valores entre $-20,0$ e $-30,0$ e ${ }^{147} \mathrm{Sm} /{ }^{144} \mathrm{Nd}$ concentrada no intervalo de 0,08 e 0,12 . O modelamento isotópico de $\mathrm{CNd}_{(2000)}$ para o TAM apresentam valores que variam de $-11,28 \mathrm{a}+1,73$. As idades $\mathrm{T}_{\mathrm{DM}}$ mais jovens obtidas no TAM, no geral localizam-se no limite entre o TAM e o TAP, em zonas miloníticas. Os valores positivos e fracamente negativos de $\mathrm{CNd}_{(2000)}$ sugerem a contribuição de materiais/fontes juvenis na formação das rochas deste terreno. Já os valores mais negativos sugerem retrabalhamento de fontes crustais arqueanas.

O Complexo Sertânia conforme já exposto, trata-se de uma seqüência de rochas metassedimentares dentro do TAM. Não há diferenças significativas entre os padrões isotópicos do TAM e do Complexo Sertânia, sendo as idades $\mathrm{T}_{\mathrm{DM}}$ paleoproterozóicas $(1,89$ a 2,17 Ga), $\mathrm{CNd}_{(0)}$ com valores entre -15,63 e -23,64, ${ }^{147} \mathrm{Sm} /{ }^{144} \mathrm{Nd}$ com valores entre 0,09 a 0,11 e $\mathrm{CNd}_{(2000)}$ com valores entre $-0,21$ a $-6,11$ (fracamente negativos). A semelhança entre os padrões isotópicos dos ortognaisses do TAM com as rochas do Complexo Sertânia denota uma contemporaneidade entre a sedimentação e a acresção e geração da crosta, hipótese já discutida por Santos et al. (2004), e que é embasada nos dados obtidos de $\mathrm{U} / \mathrm{Pb}$ em zircões.

Os dados Rb-Sr do TAM e do Complexo Sertânia (Fig. 9) alinham-se a reta de regressão de referência de 2100 Ma. Este padrão ressalta a origem paleoproterozóica para o TAM e a homogeneização isotópica do sistema $\mathrm{Rb}$-Sr neste período. De modo geral, o gráfico é coerente com a situação do contexto litoestrutural regional, de um terreno antigo (paleoproterozóico, com possíveis relictos arqueanos) fazendo parte do embasamento de uma província Brasiliana, submetido a níveis diferentes de regeneração tectônica e re-homogeneização isotópica no Neoproterozóico.

O Terreno Rio Capibaribe apresenta uma carência de dados isotópicos na região estudada, sendo que os trabalhos de Sá et al. 2002, Neves et al. 2006 apresentam idades U-Pb paleoproterozóicas e mesoproterozóicas em diferentes ortognaisses deste terreno. As amostras do TRC analisadas correspondem a rochas miloníticas de composição granítica e de um granito (Granito Timbaúba), ocorrem ao longo do contato com o TAM na Zona de Cisalha- mento Congo/Cruzeiro do Nordeste. Os dados isotópicos de Nd apresentam idades $\mathrm{T}_{\mathrm{DM}}$ mesoproterozóicas $(1,41$ a 1,68 Ga), $\mathrm{CNd}_{(0)}$ com valores entre $-10,39$ e $-10,71$, ${ }^{147} \mathrm{Sm} /{ }^{144} \mathrm{Nd}$ com valores entre 0,10 a 0,12 e $\mathrm{CNd}_{(650)}$ com valores entre $-3,192$ a $-4,18$ (fracamente negativos). Os dados obtidos no TRC apresentam um padrão isotópico que contrasta com o observado no TAM, situado a norte deste domínio, o que corrobora na delimitação e separação destas províncias geológicas.

Padrões isotópicos de Nd (granitos intrusivos) A plotagem dos dados $\mathrm{Sm}-\mathrm{Nd}$ dos granitos intrusivos na região limítrofe entre o TAM e TAP em um gráfico ${ }^{143} \mathrm{Nd} /{ }^{144} \mathrm{Nd} \mathrm{x}{ }^{147} \mathrm{Sm} /{ }^{144} \mathrm{Nd}$ (Fig. 10), apresenta uma variedade de padrões isotópicos os quais em parte são observados nas rochas encaixantes. A figura 11 apresenta os diagramas de evolução isotópica de $\mathrm{Nd}$ no tempo geológico destes granitos.

O Complexo Granítico Esperança apresenta dados $\mathrm{Sm}-\mathrm{Nd}$ com duas assinaturas isotópicas distintas. $\mathrm{Na}$ porção norte do plúton ocorrem valores de idades TDM mais antigos (1,86 a 2,16 Ga), $\mathrm{CNd}(0)$ varia de $-23,43$ a $-24,13,{ }^{147} \mathrm{Sm} /{ }^{144} \mathrm{Nd}$ com valores entre $0,08 \mathrm{e}$ 0,10 e $\epsilon \operatorname{Nd}(580)$ entre $-15,07$ a $-16,52$. A porção sul apresenta valores de idades TDM mais jovens $(1,34$ a $1,60 \mathrm{Ga}), \mathrm{CNd}(0)$ entre 23,37 a $-24,13, \mathrm{CNd}(580)$ entre $-5,76$ a $-6,01$ e ${ }^{147} \mathrm{Sm} /{ }^{144} \mathrm{Nd}$ variando de 0,08 a 0,11 . As assinaturas isotópicas, principalmente as relacionadas aos valores fortemente negativos de $\mathrm{CNd}_{(580)}$ (idade de cristalização), encontradas denotam uma participação de fontes relacionada de derivação crustal para o magmatismo do complexo granítico. A presença de dois padrões isotópicos sugere que há participação de fontes mistas na derivação crustal. Como trata-se de um granito situado no limite de dois terrenos geotectônicos

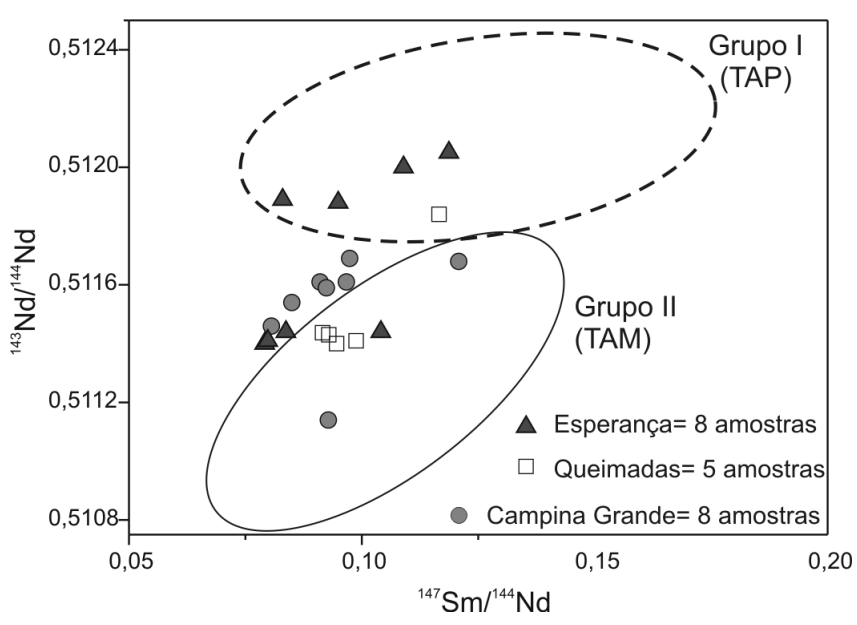

Figura 10 - Gráficos ${ }^{143} \mathrm{Nd} /{ }^{144} \mathrm{Nd} \times{ }^{143} \mathrm{Sm} /{ }^{144} \mathrm{Nd}$ para rochas graníticas intrusivas nos terrenos Alto Pajeú (TAP) e Alto Moxotó (TAM). As elipses delimitam agrupamentos de dados que apresentam comportamentos isotópicos parecidos e relacionados como grupos I e II, que respectivamente representam os padrões isotópicos observados no TAM e TAP. 

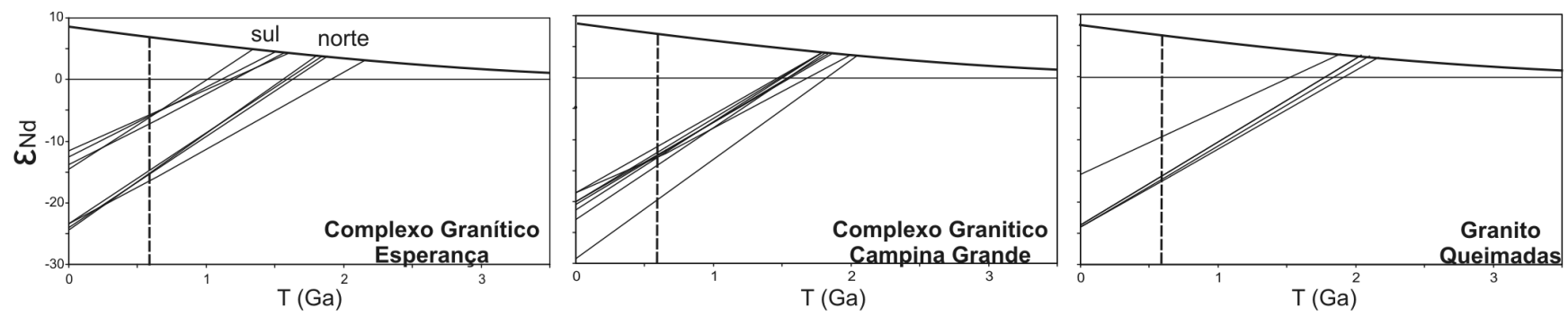

Figura 11 - Diagramas de evolução isotópica de Nd no tempo geológico para as rochas graníticas intrusivas nos terrenos Alto Pajeú (TAP) e Alto Moxotó (TAM).

(TAP e RGN) é esperado que os magmas gerados apresentem contribuições do reservatório geoquímicos de ambos os terrenos. No caso, as assinaturas com TDM mais antigas podem estar associada a fontes crustais ligadas ao RGN (Van Schmus et al. 1995, Dantas, 1996), enquanto as mais jovens ao TAP.

Os Granitos Campina Grande e Serra Redonda apresentam o predomínio de padrões isotópicos distintos aos observados no TAM e TAP. Apresentam valores de $\mathrm{T}_{\mathrm{DM}}(1,78$ a $2,0 \mathrm{Ga}), \mathrm{C}_{\mathrm{Nd}}(0)$ entre $-18,57 \mathrm{e}$ $-29,1, \epsilon_{\mathrm{Nd}}(580)$ fortemente negativos $(-11,22$ a $-21,48)$ $\mathrm{e}^{147} \mathrm{Sm} /{ }^{144} \mathrm{Nd}$ variando de 0,08 a 0,12 . Os valores fortemente negativos de $\epsilon_{\mathrm{Nd}}(580)$ ressaltam o caráter de rochas associadas a fusão de crosta continental. A distribuição dos dados Sm-Nd destes granitos no gráfico ${ }^{143} \mathrm{Nd} /{ }^{144} \mathrm{Nd} \mathrm{x}{ }^{147} \mathrm{Sm} /{ }^{144} \mathrm{Nd}$ (Fig. 9) apresenta um padrão levemente deslocado das elipses delimitadas pelo comportamento isotópico observadas no TAM e TAP. Este fato sugere a participação de fontes mistas na geração dos magmas deste granito, como ambos os granitos situam-se no limite entre o TAM e TAP, esta interpretação é razoavelmente viável.

O Granito Queimadas apresenta um padrão associado a $\mathrm{T}_{\mathrm{DM}}$ paleoproterozóicas $(>1,8 \mathrm{Ga}), \mathrm{C}_{\mathrm{Nd}}(0)$ com valores entre $-15,0$ e $-30,0$. e $\epsilon_{\mathrm{Nd}}(570)$ entre $-9,80$ a $-16,65$. Os valores isotópicos sugerem uma compatibilidade de magmas formados por refusão de crosta continental inferior provavelmente do TAM, no qual este granito é intrusivo.

Os dados $\mathrm{Rb}-\mathrm{Sr}$ referentes aos granitos Esperança, Campina Grande, Serra Redonda e Queimadas (Fig. 12), apresenta um padrão isotópico alinhado a reta de regressão de referência de $580 \mathrm{Ma}$. Esta reta de referência é compatível com as idades de cristalização obtidas por U-Pb representativas da colocação dos plútons na crosta (Almeida et al. 2002a e b, Archanjo \& Fetter 2004, Sampaio et al. 2003 e Guimarães et al. 2004).

CONSIDERAÇÕES FINAIS O sistema isotópico Sm-Nd é uma ferramenta importante que auxilia a caracterização e individualização das unidades geotectônicas na Zona Transversal, devido à presença de duas assinaturas isotópicas distintas (grupos I e II), que delimitam com precisão dois períodos principais de acresção e formação de crosta. A partir do reconhecimento destas duas assinaturas isotópicas e com seu uso aplica-

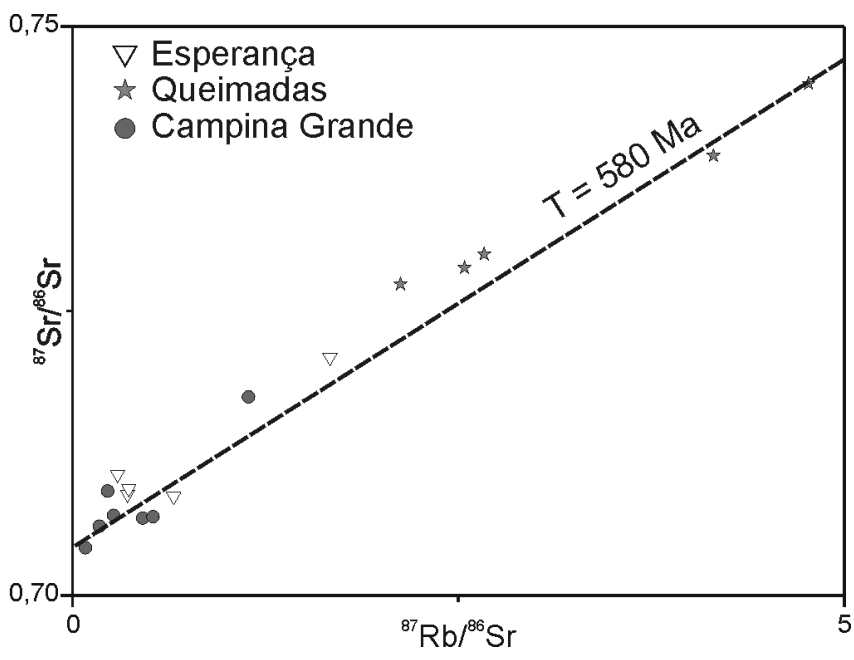

Figura 12 - Gráfico ${ }^{87} \mathrm{Rb} /{ }^{86} \mathrm{Sr} \mathrm{x}^{87} \mathrm{Sr} /{ }^{86} \mathrm{Sr}$ para rochas graníticas intrusivas nos terrenos Alto Pajeú (TAP) e Alto Moxotó (TAM).

do junto à cartografia geológica foi possível refinar as unidades geotectônicas mapeadas.

As assinaturas isotópicas $\mathrm{Sm}-\mathrm{Nd}$ do Grupo I, são relacionadas ao TAP e provavelmente refletem um período de acresção crustal relacionado ao "Evento Cariris Velhos" (Brito Neves et al. 1995) de idade eoneoproterozóica. Este período de acresção crustal é evidenciado pelos valores de $\mathrm{CNd}_{(950)}$ com predomínio de valores fracamente positivos e negativos e substanciada com as datações U-Pb nas rochas pertencentes ao TAP de idade eoneoproterozóicas (Brito Neves et al., 2001a, Brito Neves et al., 2005 etc). No entanto, a questão do "Evento Cariris Velhos" como uma orogênese permanece em aberto, sendo que na área estudada, não há evidências de que a deformação registrada nas rochas associadas a este evento seja anterior a deformação brasiliana.

O padrão isotópico do Grupo II é associado a um período mais antigo de acresção crosta relacionado as rochas paleoproterozóicas e a rochas remanescentes arqueanas. Este evento acrescionário apresenta suas assinaturas isotópicas marcadas no TAM, Domínio Rio Grande do Norte e em porções isoladas no TAP. Sugere uma correlação litoestratigráfica destes terrenos e deste modo, compondo os mesmos o arcabouço tectônico da Zona Transversal, posteriormente retrabalhados no Neoproterózoico. 
As assinaturas isotópicas dos dois eventos acrescionais de crostas são observadas nas intrusões graníticas da Zona Transversal, o que indica as contribuições dos terrenos Alto Moxotó e Alto Pajeú como fontes crustais para o magmatismo regional. Os granitos são associados a fontes derivadas de fusão de crosta continental.

As idades $\mathrm{U} / \mathrm{Pb}$ delimitam três principais períodos de magmatismo (cristalização de rocha) na Zona Transversal na área de estudo. Os primeiros são associados aos eventos de acresção e geração de crosta no Paleoproterozóico e no Eoneoproterozóico. E o ultimo asso- ciado ao magmatismo brasiliano das intrusões graníticas. Estes eventos também são registrados pelos dados isotópicos $\mathrm{Rb}$-Sr, que ocorrem alinhados as retas de regressão de referência de $2100 \mathrm{Ma}, 950 \mathrm{Ma}$ e $560 \mathrm{Ma}$. Os dados $\mathrm{Rb}-\mathrm{Sr}$ refletem a homogeneização isotópica nestes períodos, ou por eventos magmáticos ou por metamorfismo.

Agradecimentos Os autores agradecem à FAPESP (processos: 02/13677-4 e 02/14687-1) pelo apoio financeiro, ao Centro de Pesquisas Geocronológicas do IGc/ USP (CPGeo) e ao Prof. Dr. Carlos José Archanjo pelas discussões dos dados e auxilio nos trabalhos de campo.

\section{Referências}

Allegre C.J. \& Ben Othman D. 1980. Nd-Sr relationship in granitoid rocks and continental crust development: a chemical approach to orogenesis. Nature, 286:335-342.

Almeida C.N. 1999. Caracterização petrológica e geoquímica do magmatismo brasiliano na faixa de dobramentos Pajeú-Paraíba, região de Campina Grande - Queimadas, Estado da Paraíba, Nordeste do Brasil. Tese de doutorado,Centro de Tecnologia e Geociências, Universidade Federal de Pernambuco, 300 p.

Almeida C.N., Guimarães I.P., Silva Filho A. F. 2002 a. Petrogênese de rochas plutônicas félsicas e máficas na província Borborema, NE do Brasil: O complexo Cálcio Alcalino de Alto-K de Campina Grande. Rev. Bras, de Geoc., 32:205-216.

Almeida C.N., Guimarães I.P., Silva Filho A. F. 2002b. AType Post-collisional Granites in the Borborema Province- NE Brazil: The Queimadas Pluton. Godwana Research, 5:667-681.

Almeida F.F.M.de, Hasui Y., Brito Neves B.B., Fuck R.A. 1981 Brazilian structural provinces: na introduction. Earth-Sci.Reviews, 17:1-21

Archanjo C.J. \& Fetter A.H. 2004. Emplacement setting of the granite sheeted pluton of Esperança (Brasilian Orogen, Northeastern Brazil). Precambrian Research, 135:193-215.

Archanjo C.J., Hollanda M.H.B.M., Rodrigues S.W.O., Brito Neves B.B., Armstrong R. 2007. Fabrics of pre- and syntectonic granite plutons and chronology of shear zones in the Eastern Borborema Province, NE Brazil. Journal of Structural Geology, 30:310-336.

Arndt N.T. \& Goldstein S.L. 1987. Use and abuse of crustformation ages. Geology, 15:893-895.

Barbarin B. 1999. A review of the relationships between granitoid types, their origin and geodynamic environment. Lithos, 46:605-626.

Ben Othman D., Fourcade S., Allégre C.J. 1984. Recycling process in granite-granodiorite complex genesis: the Querigut case studied by $\mathrm{Nd}-\mathrm{Sr}$ isotope systematic. Earth and Planetary Science Letters, 69:290-300.

Brito Neves B.B., Van Schmus W.R, Santos E.J, Campos Neto M.C.C. 1995. O Evento Cariris Velhos na Província Borborema: integração de dados, implicações e perspectivas. Rev. Bras, de Geoc., 25:151-182.

Brito Neves B.B., Santos E.J., Van Schmus W.R. 2000. Tec- tonic history of the Borborema Province. In: Cordani U.G. Milani. E.J., Thomaz Filho A., Campos D.A. (eds.) Tectonic evolution of the South America. $3^{\text {st }}$ International Geological Congress, p.151-182.

Brito Neves B.B., Campos Neto M.C.C., Van Schmus W.R., Santos E.J. 2001a. O Sistema Pajeú-Paraíba e o Maciço São José do Campestre no Leste da Borborema. Revista Braileira de Geociências., 31:173-184.

Brito Neves B.B., Campos Neto M.C.C., Van Schmus W.R., Fernandes M.G.G., Souza S.L. 2001b. O Terreno Alto Moxotó no Leste da Paraíba (Maciço Caldas Brandão). Revista Braileira de Geociências, 31:185-194.

Brito Neves B.B., Van Schmus W.R., Kozuch M., Santos E.J., Petronilho L. 2005. A Zona Tectônica Teixeira Terra Nova-ZTTTN -Fundamentos da Geologia Regional e Isotópica. Revista do Instituto de Geociências - USP, Série Cientifica, 5:57-80.

Dantas E.L. 1996. Geocronologia U/Pb e Sm/Nd de terrenos Arqueanos e Paleoproterozóicos do Maciço Caldas Brandão, NE Brasil. Tese de Doutorado, Instituto de Geociências e Ciências Exatas, UNESP, 208p.

DePaolo D.J. 1981. Neodymium isotopes in the Colorado Front Range and crustal-mantle evolution in the Proterozoic. Nature, 291:193-196.

DePaolo D.J. 1988. Neodymium Isotope Geochemistry: An Introduction. New York: Springer,187p.

DePaolo D.J., Linn A.M., Schubert G. 1991. The continental crust age distribution methods of determing mantle separation ages from $\mathrm{Sm}-\mathrm{Nd}$ isotopic data and aplication the southwestern United States. Journal of Geophysical Research, 96:2071-2088.

Dickin A.P. 1998. Nd isotope mapping of a cryptic continental suture, Grenville Province of Ontario. Precambrian Research, 91:433-444.

Fernandes T.M.G. 1997. Estudos Geológicos e Geocronológicos Complementares a parte sul do Maciço Caldas Brandão-PB. Dissertação de Mestrado, Instituto de Geociências e Ciências Exatas, UNESP, 106p.

Ferreira V.P., Sial, A.N., Pimentel, M.M., Moura, C.A.V. 2004. Intermediate to acidic magmatism and crustal evolution in the Transversal Zone, Northeastern Brazil. In: Mantesso-Neto V., Bartorelli A., Carneiro C.D.R., Brito Neves B.B. (eds.) Geologia do Continente Sul-Americano: Evolução da Obra de Fernando Flávio Marques de 
Almeida. Editora Beca. pp:189-201.

Guimarães I.P. \& Brito Neves B.B. 2003. Caracterização geoquímica de parte do plutonismo Eo-Neoproterozóico no limite norte do domínio estrutural central da Província Borborema. In: Congresso Brasilerio de Geoquímica, 9, Resumos expandidos, p.594-597.

Guimarães I.P., Almeida C.N., Silva Filho A. F. 2002. Granitoids marking the end of Brasiliano (Pan-African) Orogênese within the Central Tectonic Domain of the Borborema Province. Revista Brasileira de Geociências, 30:177-181.

Guimarães I.P., Silva Filho A.F., Almeida C.N., Van Schmus W.R., Araújo J. M.M., Melo, S.C., Melo, E.B. 2004. Brasiliano (Pan-African) granitic magmatism in the $\mathrm{Pa}-$ jeú-Paraíba belt, Northeast Brazil: an isotopic and geochonological approach. Precambrian Research, 135:2353.

Kozuch M., Bittar S.B., Van Schmus W.R.; Brito Neves B.B. 1997. Late Mesoproterozoic and Middle Neoproterozoic Magmatism in the Zona transversal of Broborema Province. In: Simpósio de Geologia do Nordeste, 17, Resumos Expandidos, p.47-50.

Kozuch M. 2003. Isotopic and trace element geochemistry of early Neoproterozoic gneissic and metavolcanic rocks in the Cariris Velhos Orogen of Borborema Province, Brazil, and their bearing on tectonic setting. Tese de Doutorado, University of Kansas, 199p.

Jacobsen S.B. \& Wasseburg G.J. 1984. Sm-Nd isotopic evolution of chondrites and achondrites. Earth Planet Science Letters, 67:139-155.

Leite P.R.L.B., Bertrand J.M., Lima E.S., Leterrier J. 2000. Timing of granitic magmatism in the northern Borborema Province, Brazil: a U-Pb study of granitoids from the Alto Pajeú Terrain. Journal of South America Eartn Sciences, 13:549-559.

Mariano G., Neves S.P., Silva Filho A.F., Guimarães I.P. 2001. Diorites of the high-K calc-alkalic association: geochemistry and $\mathrm{Sm}-\mathrm{Nd}$ data and implications for the evolution of the Borborema province, northeast Brazil. International Geology Review, 43:921-929.

Michard A., Gurriet P., Soundant M., Albarade F. 1985. Nd isotopes in French Phanerozoic shales: external vs internal aspect of crustal evolution. Geochimical Cosmochimical Acta, 49:601-610.

Millesenda C.C., Liew T.C., Hofmann A.W, Kohler H. 1994. $\mathrm{Nd}$ isotopic mapping of the Sri Lank basement: updade, and additional constraints from Sr Isotopes. Precambrian Research, 66:95-110.

Neves S.P. 2003. Proterozoic history of the Borborema province (NE Brazil): Correlation with neighboring cratons and Pan-African belts and implications for the evolution of western Godwana. Tectonics, 22:1031.

Neves S.P., Mariano G., Guimarães I.P., Silva Filho A.F., Melo S.C. 2000. Intralithospheric differentiation and crustal growth: evidence from the Borborema Province, Northeastern Brazil. Geology, 28:519-522.

Neves S.P., Bruguier O., Vauchez A., Bosch D., Silva J.M.R., Mariano G., 2006. Timing of crust formation, deposition of supracrustal sequences, and Transamazonian and Brasiliano metamorphism in eastern Borborema Prov- ince (NE Brazil): implications for western Gondwana assembly. Precambrian Research, 149:197-216.

Oliveira R.G. \& Santos E.J. 1993. Seção geológica-geofísica e inferência geotectônicas na porção centro-sul da Província Borborema. In: Congresso Brasileiro de Geofísica, 3, Resumos expandidos, p.643-647.

Sampaio M.A, Guimarães I.P., Almeida C.N., Carmona L.C.M. 2003. Rb-Sr and Sm-Nd isotope geochemistry of granitoids from the Esperança granitic complex, Paraíba state, Borborema Province, Northeast Brazil. In: South Americam Syposium of Isotope Geology, 4, Extended Abstract, p.122-123.

Santos E.J. 1995. Complexo Granítico Lagoa das Pedras: acresção e colisão na região de Floresta (Pernambuco), Província Borborema. Tese de Doutorado, Instituto de Geociências, USP, 220p..

Santos E.J. \& Medeiros V.C. 1999. Constraints from granitic plutonism on proterozoic crustal grownth of the Zona Transversal Domain, Borborema Province, NE Brazil. Rev. Bras. de Geoc., 29:73-84.

Sá J.M., Bertrand J.M., Leterrier J., Macedo M.H.F. 2002. Geochemistry and geochronology of pre-Brasiliano rocks from the Transversal Zone, Borborema Province, Northeast Brazil. Journal of South American Earth Sciences, 14:851-866.

Santos E.J, Van Schmus W.R., Brito Neves B.B., Oliveira R.G., Medeiros V.C. 1999.Terrane and their boundaries in the Proterozoic Borborema Province, Northeast Brazil. In: Simpósio Nacional de Estudos Tectônicos (SNET), 7, resumos expandidos, p.121-124.

Santos E.J., Ferreira C.A., Silva Júnior J.M.F. 2002. Geologia e recursos minerais do Estado da Paraiba. CPRM - Serviço Geológico do Brasil, 142p, 2 mapas escala 1:500.000.

Santos E.J., Nutman A.P., Brito Neves B.B. 2004. Idades SHRIMP U-Pb do Complexo Sertânia: implicações sobre a evolução tectônica da Zona Transversal, Província Borborema. Revista do Instituto de Geociências - USP, Série Cientifica, 4:1-12.

Sato K. 1998. Evolução crustal da Plataforma Sul-Americana, com base na geoquímica isotópica $S m-N d$. Tese de Doutoramento, Instituto de Geociências, USP, 300p.

Sato K. ,Tassinari C.C.G., Kawashita K., Petronilho L. 1995. O método geocronológico Sm-Nd no IG/USP e suas aplicações. Anais da Academia Brasileira de Ciências, 67:312-335.

Van Schmus W.R., Brito Neves B.B., Hackspacher P.C., Babinski M. 1995. U-Pb and Sm-Nd geochronological studies of the eastern Borborema Province, Northeastern Brazil: initial conclusions. Journal of South American Eath Science, 8:267-288.

Zartman R.E. Lead Isotopic Provinces in the Cordillera of Western United States and their geologic Significance. Economic Geology, 69:792-805.

Manuscrito ID 8000 Submetido em 23 de maio de 2007 Aceito em 23 de junho de 2008 Sistema eletrônico de submissão 